\title{
Elucidating the Role of Heat Shock Protein in Diabetic Retinopathy
}

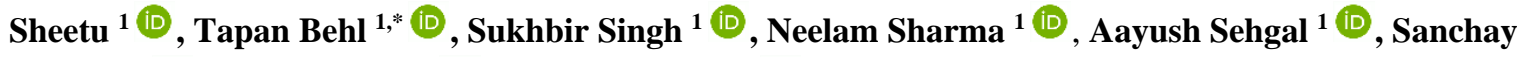 \\ Sharma $^{1}$ (D), Abdul Hafeez ${ }^{2}$ (D), Simona Bungau 3 iD \\ Chitkara College of Pharmacy, Chitkara University, Punjab, India \\ Glocal School of Pharmacy, Glocal University, Mirzapur Pole, Saharanpur, Uttar Pradesh, India \\ Department of Pharmacy, Faculty of Medicine and Pharmacy, University of Oradea, Romania \\ Correspondence: tapan.behl@ chitkara.edu.in
}

Scopus Author ID: 56560241200

Received: 31.01.2021; Revised: 27.02.2021; Accepted: 2.03.2021; Published: 7.03.2021

\begin{abstract}
The rising world-wide health and the economic burden were caused by diabetes and associated complications. Cataract genesis and retinopathy are eye-catching forms of diabetes, which are the most important cause of blindness in the workforce. Notwithstanding various research and recent advances, it is still important to thoroughly elucidate the disease's exact pathophysiology and establish new and effective treatment methods for this chronic disorder. Highly preserved protein families (HSPs) act as defensive moles, which play a wide range of functions and can be manifested in response to various cell stresses. Numerous recent studies have demonstrated their presence in multiple eye conditions [1], including diabetic retinopathy. Earlier identification and timely treatment of visual DR has reduced visual loss incidence and development. To develop new successful preventative strategies in the early stages of DR, a multidisciplinary approach is needed. Moreover, clinical trials have shown correlations between diabetic complications and altered HSP and anti-HSP circulating levels. This makes HSP a therapeutic opportunity that is exciting and could be useful as a clinical biomarker. However, this research area is still very young, and further studies are needed both in the field of experimental diabetes and in humans to gain a complete understanding of HSP relevance.
\end{abstract}

Keywords: heat shock proteins; diabetes; diabetic retinopathy; molecular chaperons; small heat shock proteins (sHSPs).

(c) 2021 by the authors. This article is an open-access article distributed under the terms and conditions of the Creative Commons Attribution (CC BY) license (https://creativecommons.org/licenses/by/4.0/).

\section{Introduction}

Ritossa in 1962 from Italy revealed Heat shock proteins (HSPs), a group of proteins highly conserved that are expressed under different types of stress responses [1]. Heat shock proteins can also be termed as stress proteins and are multi-molecular complexes that work as molecule chaperone proteins under normal growth conditions and regulate role in protein rendering, misfolding accumulation of proteins, and changes in cell physiology [2]. Many HSP family members constitutively function as molecular chaperones [3], peptide stabilizers during growth, hypoxia under stress, resynthesizes during cell repair, and research on their role in many disease areas, including adding, cancer, immunology, signaling, etc. have also been enumerated. It is observed that in recent times, HSPs are easily multiplied in different HSPs in response to cell stress as their most significant role is to defend cells against the adverse effects of stress. The factors triggered by species that initiate from bacteria to living organisms can trigger HSPs, which are the proteins most conserved among species [4]. Many other diseases 
and pathogens are often controlled with a variety of factors such as solar radiation, heavy metal or ethanol therapy, ischemia, hypoxia, and the genes of these proteins. Protein synthesis reductions are seen in a heat shock state, while hyperthermia increases in HSP, mRNA, and protein synthesis. The total protein synthesis under hot shock conditions is decreased. At the same time, the first few hours of hyperthermia are enhanced by HSP mRNA and protein synthesis [5]. In contrast, certain stages of protein synthesis, such as RNA splicing, are inhibited at high temperatures [6].

\section{Role of Heat Shock Proteins in Diseases}

Conventional Growing research indicates that HSPs may play a significant role in diseases, such as non-alcoholic fatty liver disease (NAFLD) [7], Huntington disease [8], and type 2 diabetes avoiding insulin resistance and developing type 2 diabetes. The transgenic overexpression of HSPs, on the other hand, has an advantage in animal obesity or metabolic disease models [9-15]. Especially in developing obesity, resistance to insulin, and type-2 diabetes, it is known for skeletal HSP muscle levels. Since skeletal muscle is the key fiber responsible for insulin-stimulated glucose [16], the expression of HSP in the skeleton during obesity, insulin resistance, and type 2 diabetes has been studied by several researchers. Skeletal muscle expression HSP72 (HSP70 in animals) is reversed compared to the proportion of body fat and blood glucose in healthy individuals $[17,18]$. In comparison, the skeletal muscles in all patients with diabetes type 2 and patients with insulin resistance decreased dramatically in HSP72, mRNA, and protein expression. Many have also reported that the expression levels of HSP72, through the development of obesity and metabolic diseases (i.e., insulin resistance and type 2 diabetes), are closely linked with adiposity. Glucose can also partially control HSP levels of expression [18-21].

Numerous studies have depicted their role in ocular disease, including Diabetic Retinopathy (DR), where hyperglycemia is the main pathogenic factor [21]. Hypoxia-inducible factor 1 (HSF 1) acts as an angiogenesis stimulator resulting in upregulation [22], but HSF-1 is further split into HSF1alpha (Oxygen Dependent) and HSF 1beta (Nuclear Sub Unit) [23] subunits. In Diabetic Retinopathy (DR) HSF-1 and Vascular endothelial growth factor (VEGF) plays the most important role in various stages [24]. It is seen that HSF 1 modulates the expression of chaperones to respond to high-temperature stress, oxidative stress, and proteotoxic agent exposure [25-27]. HSF1 is a transcription regulator, as an inactive monomer HSF1 free of repression by chaperones contributes to HSF1 trimerization and activation, HSF1 continues in the cytoplasm. HSF1 is later transported to the matrix, where it binds to protected heat shock elements and transcribes target genes, including HSPs. For the quality regulation of protein, HSP's are important with the aid of the protein folding or the leading of malfunctioning proteins in sufficient degradation, like the proteasome and or the lysosome [28]. The research recommends assessing patients with ischemic eyes the following variables in the serum of diabetic patients and the degree of HSP70 and HSF-1alpha [29].

\section{Role of Heat Shock Proteins in Diseases}

\subsection{Heat shock protein 27 (HSP-27).}

HSP 27 is also called beta-1 (HSPB1) or HSP25 heat shock protein. It is one of the least evolved and stressful HSPs [30-33]. For example, HSP 27 expression in rat hippocampus and visual systems has been increased after optic nerve transaction hyperthermia [34,35]. In four 
separate models of retinal degeneration, Chidlow et al. tested the expression level HSP 27. The expression used an AATE model, N-Methyl-d-aspartate (NMDA) mediated excitotoxicity [36], and a chronic hyper-fusion pattern via bilateral carotid occlusion. The phenomenon used is an acute axonal optic nerve crush model. An increased expression of HSP 27 at protein and mRNA levels in the retina was observed in all identified models [37]. HSP 27 may play a significant part in pathological pathways in the case of glaucoma. Higher serum titers of HSP 27 antibody were identified in Glaucoma patients [38,39]. In retinas of glaucoma patients, an improvement in HSP 27 may also be found [40]. HSP 27 is also protective for apoptosis avoidance. Intracellular HSP 27 is observed to bind cytochrome $\mathrm{c}$ and inhibit cytochrome $\mathrm{c}$ mediation of Apaf-1 interactions with procaspase 9 in human leukemia cell U937 (the cells are myelomonocyte cells, which can be inducted into macrophages) [41]. Furthermore, HSP 27 is a cytoskeleton stabilizer that supports actin filaments during oxidative stress. The inhibition of HSP 27 in a light-induced retinal degeneration pattern has also caused a defensive effect on photoreceptor cells [42].

Glaucoma is the most prevalent cause of permanent vision loss, in addition to agerelated macular degeneration and retinopathy, and will rise further by 2030 [43]. Glaucoma is a multi-factorial condition characteristic of retinal ganglion cell depletion and optic nerve degeneration [44]. The present research is nevertheless based on many pathways that lead to glaucoma, elevated intraocular pressure [45], oxidative stress [46], and excitotoxicity [47], as well as immunological processes. Several reports have shown that the auto-antimicrobial titers against various proteins and antigens are changed by glaucoma patients, including phosphatidylserine [47], neuron-specified enolases [48], Calcium Protein B (S100B) [49] and Heat Shock Proteins (HSP) [50-52]. HSPs have a well-maintained structure and are caused by multiple physiological and environmental stressors. The chaperone acts by stabilizing new proteins and replenishing proteins that have been weakened by multiple stresses [53].

\subsection{Heat shock protein 47 (HSP 47) or serpin H1.}

The collagen-specific chaperone, the glycoprotein present in ER, is the heat shock protein 47 (HSP47). In specific, HSP47 inhibits collagen aggregation by pro-collagen binding in RE and promotes a helix's formation three times. Collagen ripening includes studies in the gene ablation of confirmed HSP47 because the HSP47 deficient cells limited auto aggregate procollagen in ER. In the context of diabetes, a great deal of research focused on the role of HSP47 in diabetic neuropathy, both in neuropathy and as a key determining factor of renal failure, as an inappropriate accumulation of extracellular matrix elements such as collagen [54]. In DM, much of the study focuses on the significance of the HSP47 for DN, a hallmark of diabetic neuropathy and a primary determinant for loss of renal function in excessive deposition of extracellular matrix components, such as collagen. The kidney tissue analysis of DN patients found that the improved manifestation of HSP47 was found in the sclerotic glomeruli through the overproduction of type III and type IV kidney-residing collagen. Similarly, in the advanced expression of collagen in the experimental DN, glomerulosclerosis, and interstitial tubules fibrosis, simultaneous growth in tubular epithelial cells has also been achieved in type III and type IV exposures [55].

Further, in the transformation to epithelial-mesenchymal disorders, HSP 47 is the leading case renal fibrosis is underlying progressive kidney failure, like DN. Overexpression of DM-induced HSP47 was involved in the development of Era. Not only the transfer of growth factor $\beta 1$ (TGF- $\beta-1)$ and collagen, but the activation of HSP 47 was also resisted by the 
regulator of AGE in test diagnosis of OPB-9195. Furthermore, mesangial cell vulnerability to AGEs led to the expression of HSP47 by TGF- $\beta 1$ [56]. Although in vitro experiments on proximal tubular molecules demonstrate that signal activation molecules are involved, the kinases of extra cells (ERK 1/2) and Jun kinase (JNK), which are regulated by the signals, are not thoroughly elucidated. And if the TGF- $\beta 1$ induces HSP47 is intracellular.

The potential role of HSP47 in other chronic DM complications is limited. However, the development of collagen in both human and experimental diabetes was important in the healing process, and the expression of HSP47 decreased in injuries. It indicates that the DM sense may require inadequate HSP47 induction. In other chronic DM complications, the potential function of HSP47 is limited. However, in both human and experimental diabetes, collage production was substantial, and the expression of HSP47 in injuries declined. It shows that the context of DM may need insufficient HSP47 induction.

\subsection{Heat shock protein D1-heat-shock protein60 (HSP 60).}

HSP60 is predominantly found in mitochondria and can be found both on cytosol surfaces and the nucleus. Because of their risks to mitochondria, HSP60 is regulated and transmitted to the cell membrane and Golgi devices. The HSP60 internalizes lipid endosomes in the cell membrane via the raft membrane. Besides, Golgi vesicles can transfer free soluble HSP60 molecules to the extracellular environment. A potential biomarker of inflammatory diagnosis in the brain cells may be the free or exosomal bound HSP60. Narcotic extracellular expression of HSP60 was observed in various inflammatory disorders, including cancer, diabetes, atherosclerosis, rheumatoid arthritis, neuro-inflammatory disease, target tissues, and body fluids blood, saliva, and urine.

Heat- shock protein60 is the target for atherosclerosis T-cells and antibody reactions, human HSP 60 leads to trigger gene expression and further leads in promoted Th1 (T-helpercell-1) cytokines IL-12 (Interleukin 12) and IL-15 (Interleukin15, autologous HSP 60). Patients with diabetes, atherosclerosis, and cardiomyopathy are found to suffer from this condition. Further experiments show that HSP 60 is translocated from mitochondria, a human HSP 60 housing gene, linked to a green fluorescent (GFP) protein bound at the C-terminal. Within $\mathrm{DH} 5 \alpha$ in $\mathrm{E}$, the plasmid replicates and purified with a plasmid extraction clear of Endotoxin (DH5 $\alpha$ ). Human cervical cancer cell lines transfected by endotoxin-free DNA have been shown to impact HSP 60 expression in mammalian cells, resulting in a regulated stress therapy without the undesirable effect created by DH5 $\alpha$ endotoxin.[57] The HSP 60-GFP DNA is found to be endotoxin or lipopolysaccharide expression in mammalian cells. The transfected HeLa cells and the translocation of the HSP 60-GFP signal [57] are stressed by high-glucose and sodium azide. The translocation of HSP 60-GFP from mitochondria can be related to high-glucose. The findings confirm that published evidence indicating higher glucose levels may play a part in translocating HSP 60 to extracellular fluids and mitochondria. It was also found that fluorescent confocal microscopy can help detect the HSP 60 biomarker's movement under stress and therapy. In contrast, serum HSP60 levels were substantially increased due to increased mitochondrial and inflammatory stress in patients with type 2 diabetes and morbid obesity. Type 1 diabetes testing was performed with the altered HSP60 peptide p277 (DiaPep277) variant with very high reactivity. The high serum level HSP60 also raises the risk of systemic obesity. HSP60 can also constitute a future therapeutic goal for and complications of diabetes. Interestingly, in certain tissues such as the brain, coronary, and subcutaneous adipose, type 2 diabetes shows a reduced expression of the intracellular HSP60. Importantly, a drop in 
intracellular specific HSP60 levels typically in diabetic people detected and avoided by administered adiponectin is closely associated with inflammation, mitochondrial, reactive oxygen species production, and insulin resistance.

\subsection{HSP70 or heat shock protein A.}

Active Heat shock proteins are considered anti-inflammatory and regulated both by the TLR-2 (Toll-like Receptor) and TLR-4 activation [58,59]. HSP70 includes negative regulatory factors (NEFs), which play a part in the shipment, and supply of protein organelles. The brain's cortex is comparatively small in HSP70 and HSP27; both proteins are strongly inducible due to different stressors. This encompasses physical stressors [60, 61], ischemia [62], hyperthermia [63], nerve injuries [64,65], and mentally stressful disorders [66]. May include: the central nervous system, the expression of the two proteins is also regulated $[67,68]$. The Hsp70 multigene family consists of Hsc70 and Hsp70 cyto- and nuclear-located, Grp78 endoplasmic reticulum, and Hsp75. During normal development, Hsc70 is abundantly expressed. In comparison, the Hsp70 levels are controlled by development and triggered in all living organisms in response to several stressful stimuli. The protein is active and constituent (Hsc70) in various chaperoning processes, such as refolding misfolded or aggregated proteins, avoiding protein aggregation, plying and assembly, and facilitating ubiquity degradation of multi-subunit proteins. They also engage in the intracellular membrane translocation of proteins and interaction with signals. Hsp70 chaperones function by keeping existing and newly synthesized chains in a state that is responsible for plying into the media after publication [69]. Hsp70 binds unfolded proteins or partly folded them typically by contact between the chaperone and the expanded polypeptide segments with a net hydrophobic character. Furthermore, HSPA/HSP70 contributes to oxidation stress due to stress; it blocks APP and inhibits inflammation. HSP70 raises the glucose level and, with the oxidation of MMP-9 DMinduced mitochondrial defects, contributes to complex development between HSPA/HSP-70 and the metallopeptidase9 (MMP-9) matrix [70]. Chaperoning of MMP-9 into mitochondrial and enhanced mitochondrial damage caused by MMP-9 is the main function of HSPA/HSP70, although low levels of anti-HSPA in Type 2 patients are recorded. Finally, HSP plays an important function in diabetic patients' cellular stress conditions. The serum level affects the tissue in the systemic phase as the serum level increases. For HSP-mediated drugs, the systematic way of administration is better because they are less intrusive and less stressful for diabetes patients [71].

\subsection{HSP90 or heat shock protein C (HSPC).}

The most widely described heat shock inducers are which inhibit the function of HSP90, they are broadly classified into five subcategory- (1) cytosol inducible (HSPC1 or HSP90AA1), (2) cytosol inducible (HSPC2 or HSPAA2), (3) cytosol constitutive (HSPC3 or HSPAB1), (4) ER (HSPC4 or GRP94), and (5) mitochondrial (HSPC5 or TRAP1). In the unstressed cell, the activity of HSF-1 is under tight negative regulation by a complex of proteins, which includes HSP90, a major constituent of this complex [72]. HSP 90 is found in cytosol and nucleus, possessing an ATP N-terminal binding domain necessary for most of its cell functions [72]. Some HSP90 inhibitors bind in the chaperaonic A TP cycle, which leads to a degradation of non-foldable client proteins and binds HSP90 to a stress-sensitive factor, heat 
shock factor 1 (HSF-1) for silence of the transcription factor and HSP90 inhibition for HSF-1, stress respite and release [73].

ATP hydrolysis-driven molecular chaperone, which allows embryo proteins to fold up and mature, is one target for new molecular therapeutic agents: the heat shock protein 90 (HSP90). In addition to the importance of several HIV/AIDS diseases [74] to malaria [75], to neurodegenerative disorders, it has a key role in the mechanism of various oncogenic pathways [76,77]. A detailed analysis has been carried out of a mechanical life cycle of HSP90, including HSP40 and HSP40, HSP protein organization, and HSP protein interaction (HPI) $[78,79]$ after protein coordination and a co-chaperone is developed [80]. In recent times this binds to ATP and completes the natural cycle using the exothermic ADP formation to help the protein ripen. On the other hand, the protein is released by adding an enzyme to the ATP-binding site, leading to ubiquitination and proteasomal degradation [81]. Therefore, HSP90 inhibitors' classic molecular synthesis entails depleting client protein and up-regulating other heat shock proteins [82]. The description of the role and locations of various heat shock proteins is given in Table 1.

Table 1. Description of role and locations of heat shock proteins.

\begin{tabular}{l|l|l|l} 
Types of HSPs & $\begin{array}{l}\text { Molecular mass } \\
\text { kDa }\end{array}$ & Location & Role \\
\hline HSP 27 & 34 or lower & Cytoplasm & $\begin{array}{l}\text { Prevent protein unfolding aggregation and accumulation of } \\
\text { proteins }\end{array}$ \\
\hline HSP 47 & $35-54 \mathrm{kDa}$ & Cytosol & Chaperonin intermediate filament \\
\hline HSP 60 (monomer) & $55-64 \mathrm{kDa}$ & Mitochondria & Protein assembly by folding heterologous protein complex \\
\hline HSP 70 (monomer) & $65-80 \mathrm{kDa}$ & Cytoplasm & Helping Protein folding in the endoplasmic reticulum \\
\hline HSP 90 (monomer) & $81-90 \mathrm{kDa}$ & Nucleus & Helping myosin folding
\end{tabular}

\section{Association of HSPs and Diabetes}

The leading cause of preventable blindness amongst employees is diabetic retinopathy, a microvascular complication of diabetes. In another third of patients living with diabetes, this disease is also related to an increased risk for life-through systemic artery complications, including stroke, coronary heart, and cardiac failure. Recent studies have shown that the Hsp and crystalline pathophysiology of this complication could play a significant role. The essential feature of diabetic retinopathy has been crystalline upregulation in the retina, in particular, Alpha-As and Alpha-B-crystalline. Various models, including streptozotocin and diabetes caused by alloxan, have demonstrated this upregulation. During the progression of diabetes, certain Hsps, including crystallines, are greatly reregulated in the retina. Two human upregulated diabetic retina proteins were subtype 1A and subtype 8 of HS70 in a comparative analysis of the proteomic map of normal diabetic rats and streptozotocin-induced retinas. While the expression of Hsp90 was known to be upregulated under different stress conditions, the levels of HS25 in the retina of streptozotocin were decreased. In yet another study investigating Hsp90's immunoreactivity in the OLETF diabetes rats, the levels of Hsp90 were significantly elevated at age 24 weeks. This distinction may explain Hsp90's variations in diabetes type 1, multiple functions during various diabetes stages, or interindividual heterogeneity in the reaction of diabetes. Furthermore, the above section was suggested as a biomarker for microvascular diabetes complications to investigate potential anti-IgG antibodies. 363 people with diabetes of Type 1 have analyzed levels of anti-HS27, and 168 have concluded that vasculosis is not an adjunct of Type 1 [83]. 


\section{Autoimmunity and HSP}

\subsection{In type 1 diabetes.}

An autoimmune event results in the loss and subsequent decrease in insulin production of type 1 cells of the pancreatic islet beta [84]. HSPs constitute one of the possible antigens for the production of autoimmunity. For instance, T-cells, which recognize HS 60, can transmit the production of insulitis and hyperglycemia in mouse models of autoimmune diabetes (e.g., mice), anti-immune HSP 60 to beta-cell damage, as well as to young prediabetic NOD mice [85]. It is important to locate the target antigens responsible for autoimmune events to monitor beta-cell damage through immunotherapy. Vaccination of HSP 60 and related peptide p277 has effectively prevented diabetes in mice and streptozotocin-treated animals [86]. This immunotherapy can also be used to alter the immunity balance between the T-helper type 1(Th1) pathogenic autoimmune response and a defensive response of the T-helper type 1 (Th2) antibody. It is proposed that, in addition to HS60, HSP70 and p277 [87] similarly improve autoimmunity in recent cases for child and adult with type 1 diabetes. The autoimmune diabetes-prompting case is asymptomatic; HSP autoimmunity can be manipulated and altered in the future. Raz et al. [88] reported better protection of $\beta$-cell activity in type 1 diabetes in patients administered daily doses of p-277 extracted from HSP 60. Patients treated with Peptide-p277 (P-p277) still required 20\% less insulin than the other group. While this therapy's effects include regular doses, these findings show the possibility for treatment for Type 1 diabetes in changing HSP autoimmunity.

\subsection{In type 2 diabetes.}

The study reported HSP72 as only one out of 17 genes out of $>5,000$ early records of reduced expression of HSP72 in type 2 diabetes [89], which was slightly lower in insulinresistant vs. stable controls [90]. Since no correlation exists between HSP72 mRNA and the rapid accumulation of plasma glucose or insulin, it is unlikely that the chronic rise of plasma glucose in diabetes patients results in improvements in the expression of HS72. Any results support the theory that diminished HSP72 expression triggers the progression of type 2 diabetes and insulin resistance, at least in part. HSP72 expression has been reported to influence insulin susceptibility through a direct association with GLUT4 [91]. In patients with diabetes versus controls, no reduction has been reported in GLUT4 gene expression. Specifically, in type 2 muscle pathological examination and monitored patients, the intramuscular amounts of triglyceride were also evaluated. The patient population is made up of intramuscular triglycerides. These findings identify the role of HSP in the etiology of insulin resistance caused by obesity and the identification of decreased HSP72 mRNA diabetes expression.

\section{Angiogenesis in Diabetes}

The development of a new (microvascular) capillary network in response to hypoxia or other causes is angiogenesis. The angiogenesis mechanism requires local secretion of both hypoxic and promoting pericytes angiogenic factors, which cause endothelial sprouting and neovessel sprouting. This mechanism varies from the development and development of current arterial structures in response to acute arterial occlusion (i.e., exercise-induced stress) or physical forces. Earlier, the exhibition of irregular blood vessels in glomeruli in patients who have long-term type 1 diabetes was published. These effects were subsequently observed in 
patients with type 2 diabetes. The angiogenesis idea was first called the sprout from preexisting vessels in previous vascular tissue of endothelial cells (ECs). This definition has recently been generalized to include the development and restructuring process, which turns an initial vascular system into a complex network typical of mature vasculatures. Angiogenesis is a complex multi-stage mechanism involving the degradation, growth, survival, migration, and morphological changes in the extracellular matrix (ECM) of the ECs and their anastomosis into a vascular system. The perivascular ECM plays a key role in evaluating proliferative, invasive ECM during angiogenesis and local vascular cell survival responses. The variations in ECM dynamics and local vascular cells work to control the formation of new blood vessels. To encourage this wide variety of pro- and anti-angiogenic factors in an angiogenic mechanism must take concerted and synergistic action to assemble functional vessels of blood. Diabetes pathophysiologies include elevated glycemia, non-enzymatic glycemia, and lipoxidation, systemic inflammation, increased ROS, and hyperinsulinemia. Vascular cells are also exposed to abnormally elevated ROS signaling molecules for patients with diabetes, leading to unwieldy signaling pathways. The paradox that vascular dysfunction and prolonged angiogenesis coexist in various species seems to be a special function of the disease pathogenesis [67-69].

\section{Oxidative Stress in Diabetes}

Due to enhanced free radicals, the abnormal condition of imbalance in the cell redox mechanism generates oxidative stress, and unpaired electrons are reacting to cell molecules to destroy cell structure and integrity. Endogenous enzymatic and non-enzymatic antioxidants sustain the continuous accumulation of reactive oxidative species (ROS) under power. The retina is high in fatty acid and very susceptible to diabetes oxidative injury. Additional oxidative binds the four principal pathways in diabetic retinopathy, including activation of PKI, polyol, and hexosamine and the development of AGEs, which are known as significant causing factors in developing diabetic retinopathy. The ingestion of NAD+ by polyol indicates the antioxidant protection is weakened and the oxidative stress is rising more. High glucose levels, and the subsequent fructose increase due to the increased polyol pathway, contribute to the production of AGEs that cause cell dysfunction via their unique receptors. Oxidative stress is also at the core of diabetic retinopathy pathogenesis $[10,82,92]$.

\subsection{Production of ROS.s}

Cellular respiratory development of reactive oxygen species is a natural physiological process. For instance, in enzyme processes, the cytosolic Nox and the Cytochrome p450 or xanthine oxidase, ROS also can be produced. ROS produces both enzyme and non-enzyme pathways in the diabetic system, and Nox and mitochondrial ETC pathways constitute their prominent source $[10,82,93]$.

\subsection{Cytosolic ROS production.}

The Nox enzyme family constitutes the primary source of cyto-SR production, Nox2 being an active contributor to the generation of retinal ROS in diabetes. Nox 2 is a highly regulated membrane-associated enzyme that catalyzes the reduction of 1electron oxygen by oxidation of cytosolic NADPH into superoxide anion. The cytosolic subunit P47phox, P67phox, and Small GP-1 are the holoenzyme, and P22phox and GP-91phox are the membrane subunits. Relevant guanine exchange factors and GTPase activating proteins mediate 
activation/deactivation of Rac1. Rac1-Nox2 is triggered in the early stages of diabetes in the signaling axis in the retina and its capillary cells to promote intracellular ROS. TIAM (Tlymphoma invasion and metastasis genes), which is inhibited by the guanine factor, attenuates Rac1 activation and retinal ROS generation. The initial event preceding mitochondrial damage is triggered by Rac1-Nox2-ROS. While in the early stage of the disease, the concomitant growth in biogenesis/repair of mitochondrial DNA (mtDNA) compensates the mitochondrial damage from ROS, sustained mtDNA biogenesis and repair processes are overcome with sustained hyperglycemia, and a vicious ROS-type cycle causing damage to the mitochondria $[82,93]$.

\subsection{Mitochondrial ROS.}

As previously described, mitochondria also constitute the key endogenous source of free radicals, and mitochondrial ROS is produced most frequently during oxidative phosphorylation in the ETC. Complex I and complex III electron leaking contribute to a partial oxygen reduction, resulting in superoxide formation, gradually converting it into hydrogen peroxide. Low ROS concentrations are essential in intracellular signaling, but excess ROS production oxidizes cellular lipids, protein, and DNA. High-circulating glucose enhances ETC electron flow in the pathogenesis of diabetic retinopathy and decreases complex III activity to an improved generation of ROS [10,82,93].

\section{HSP and Inflammation}

Insulin resistance can result from inflammation alone. Analysis has identified a strong causal association among chronic inflammation, obesity and insulin resistance over the past few years. In insulin-sensitive organs of the liver, skeletal muscles, and adipose tissue, adipocytes or macrophages secrete inflammatory cytokines (e.g., TNF-alpha) that activate Jun amino-kinase (JNK) and I-B-kinase (IKK) JNK and IKK both inhibit and interact with the downstream signaling function of the insulin receptor. Excess deposition of lipids in the liver and adipocytes that increases lipid metabolites results from deficient insulin action (ceramide and diacylglycerol). Ses lipids specifically improve the insulin signals by activating JNK and IKK. Genetically interloping with JNK or IKK, a pharmacologic agent or an exercise defends against resistance to obesity insulin.

In type 2 diabetes, insulin-sensitive factor heat shock (HSF-1) decreases HSP expression and decreases HSP. Besides, a delayed HSP reaction is associated with impaired wound care of the diabetic disease. In animal models, the restoration of insulin production raises HSPs, while the interruption of insulin reporting results in the activation of glycogen synthase kinase-3 (GSK-3). Upon activation, GSK-3 prevents nuclear translocation through HSF-1 phosphorylate sequences 303 and 307, thus reducing HSPs. Also, the reduction of insulin signaling suppresses the activity of HSF-1 through MAP kinase pErk1 expression (mitogen-activated extracellular regulated kinase), and JNK deactivates HSF-1 [92].

\section{Heat Shock Proteins and Protein Moonlighting}

Moonlighting proteins are specific that differ from other multifunctional proteins since they conduct Two or more unique and unrelated roles, i.e., they are not promiscuous enzyme activities, where under various circumstances, different reactions are catalyzed by the same active site. Moonlighting contradicts the normal idea that enzymes act in a cell's intracellular 
or extracellular environment and stay in that position. One of the major classes of moonlighting proteins known to date is enzymes and intracellular chaperones, which have different effects on the cell's extracellular part [93]. In glycolysis, glucose breaks down, and energy is produced in the form of ATP, which latterly enters into citric acid cycles, the pathway of the pentose phosphate, and protein and DNA metabolism; there are typical "housekeeping proteins." A 3phosphate dehydrogenase (GAPDH) glyceraldehyde is the first to be seen on the surface of pathogenic streptococci. Later, several additional intra-cell/surface enzymes, such as other GAPDHs, phosphoglycerate kinase, and enolase, were observed. Some intracellular surface proteins (ICSPs) consist of chaperones (HSSP60/ HSP70), elongating factors (EF-Tu), and histone Protein Synthesis (EF-Tu) (H1). In humans and other animals, some proteins act as cell receptors. In glycolysis within the cell, GAPDH catalyzes the conversion of D-glyceraldehyde 3-phosphate to 3-phospho-D-glyceroyl phosphate in most cells but acts as a cell transferrin receptor in mammals that help in iron uptake. HSP60 is a chaperone that promotes the import of mitochondrial protein into the cell and is a high-density lipoprotein cell surface receptor due to its apo-lipoprotein a-poA-II affinity [94]. In humans, pyruvate kinase 3 (PK3) isoform two of the sperm head membrane, glutathione S-transferase $\mathrm{Mu} 3$, triosephosphate isomerase and fructose-bisphosphate aldolase, and plays a second role in interactions with egg protein zona pellucida. In bacteria, this mechanism of intracellular/surface moonlighting proteins has been commonly observed. The cytosolic proteins on the cell surface are typically used to form and create bonds with the host species by bacteria and other pathogens. Many of these proteins play important roles in inflammation, invasion, virulence, and biofilms formation. Colonizing includes host adhesion and attachment to proteins in the extracellular matrix or mucin, a member of the epithelial mucosal coating, multiple surface proteins including Fibronectin, Lamin and/or collagen. Additional moonlighting proteins are connected explicitly to proteins in the host cell surfaces. These relations contribute to an attachment of the host. Listeria uses alcohol acetaldehyde, Listeria adhesive protein that binds to intestinal epithelial cells (LAP).

The theoretical ability of extracellular HSPs to affect ecology and physiology has grown in these proteins' biological structures and functions. The treatment of cells with distilled HSPs indicates, as discussed, cell activity close to that of pro-inflammatory cytokines. Despite debate about the likelihood that pathogens in packaged goods could be responsible for at least some of the pro-inflammatory effects of HSPs [95]. It is a recent pattern to suggest at least that such HSPs are secreted [96] proteins with major human-like acts such as a tumor, coronary heart disease, diabetes mellitus, and rheumatoid arthritis (HSP10, thioredoxin, HSP 27, BiP) or antiviral (HSP 60, HSP80, HSP90) and other anti-inflammatory actions. Moreover, HSPs can bind peptides to modulate immune responses that can have repercussions for various diseases, including cancer [97], to have a direct effect upon cells. HSP70 can be used in an expressed membrane. It has been clear that the HSP70 membrane exploitation has importance in analytical, therapeutic, and imaging potential in the management and treatment of patients with cancer [98]. Taken together, the observations that HSPs can be located in the extracellular compartments and cell-dependent compartments have led to a new theory designating such proteins as lunar proteins (proteins that are capable of 'escape' cells and interact with various cell types to create many biological effects). This has culminated in the development of a paradigm. The proteins can also be labeled 'inflammatory' receptors for inflammatory mediators [99]. A variety of studies highlighted in this edition [100] and several studies that have demonstrated, and continue to demonstrate, many HSPs in the body fluids of people and animals support this new paradigm [101]. 


\section{Diabetes and HSP: Proteins Glycation}

A long-term rise in glucose is one of the serious causes of secondary diabetes conditions, such as angiopathy, neuropathy, retinopathy, a protective mechanism for antioxidants, and lipid-profile diseases. The major cause is the beginning of a sequence of reactions, which contribute to the production of Schiff-base, amadori products, and protein glycation AGEs. In patients suffering from Type 1 and Type 2 diabetes, certain tests demonstrated reduced expression of HSPs. One of the most important causes for the onset of diabetic problems was the reduction in chaperones' presence. Therefore, researchers aim to design and adapt different methods to the speech of HSPs, like chemical and medicinal compounds, some exercise, and thermo-therapy. Exercise is vital in patients with diabetes to activate HSPs. Studies indicate that the beneficial effects of exercise on diabetes have possibly been linked with HSP upregulation [102-104]. The effects of hot water were analyzed as a physical parameter in the expression of HSP70 induction. Several experiments show that HSP70 is glycated and lacks its chaperone function in the presence of elevated blood glucose concentrations. In addition to the decrease in the HSPs expression previously recorded in diabetes, glycation often decreases the activity, which is exacerbated by changes in their composition. Glycated HSPs are detected (due to misfolding) by quality control mechanisms and are rapidly eliminated from circulation.

For diabetes, this protein is not identified by monoclonal glycemia, and the test kit cannot also identify and measure this deflected protein concentration. Proposed mechanisms that affect living cells include direct impairment in the glycation of the target protein production, changes in the oxidative or carbonyl stress that leads to initiation of signal transduction deleterious pathways.

\section{Diabetic Retinopathy \& Heat Shock Protein}

Diabetic retinopathy is vision impairment. The major population of type 1 diabetes is threatened by diabetes retinopathy (DR). However, the cases as per the Union Heath Ministry first diabetes and diabetic retinopathy survey prevalence of DR is $16.9 \%$ as per $2015-2019$. The cases may rise to more than a billion by 2045 (WHO Report). The major populations aged between 20-74 years are seen under this that is one-third of the population is affected [102]. Diabetes retinopathy is classified under diabetic molecular edema (DMO) or proliferative diabetic retinopathy (PDR). DR is indicated by retinal new vascularization and formulation of microaneurysms, leading to a loss in vision [103]. DR is the fifth major reason that causes loss in vision, but vision impairment might increase with respect to the population as per the present era. As per the studies, heat shock protein (HSP) is leading with a major role in recovering insulin resistance [104]. Their major role is to maintain cellular function HSP elements role is oxidation inflammation and apoptosis. HSPs are a group of proteins that placed an efficient role in the site of protection, and the modulation is tested on an animal model for diabetes mellitus (DM) [105]. According to the report, HSP and anti-HSP antibodies are a perfect aptitude for using serum biomarkers of DM complications. HSPs are some of the highly evolutionary proteins in living organisms, and in any organism in which they were found, there is a hot-shock effect from archaebacteria to higher eukaryotes like humans. Although most heat shock response characteristics are the same, variations between organisms and species, such as the perfect temperature induced by the reaction, occur [106]. 
Crystallin belongs to the small HSP class in the retina-alpha-crystalline family. Although once synonymous with the lens, its expression and function have become apparent in other tissues, including ocular tissue such as the retina. Crystallin expression can be of interest to retinal growth, as are other heat shock proteins. Many cells in Müller, called peripapillary glial cells (PPGCs) next to the optic nerve's head, display alpha B-crystalline while the retinal development is in progress. [107]. In retinal pigment epithelium, alpha Bcrystalline is also expressed at particular stages during rat retinal development [108] instead of alpha A-crystalline. The RT-PCR quantitative study reveals that about 20 multiple crystalline genes have been expressed in adult mouse retinas. In the ganglion cell wall's nuclei, inner and outer layers, and inner parts of the photoreceptors, alpha A- and alpha B crystalline are expressed at low levels in the absence of stress [109]. It has been suggested to lead to a vector transport of Rhodopsin from the Golgae system into the rod's outer portion through their representation in the retinal photoreceptors [110]. Of note, the recent research reveals that the retinal pigment epithelium of alpha b-crystalline, pericytes, endothelial cells, and astrocytes [111] have alpha B-crystalline expression[112]. This study also shows that retinal pigment epithelium may be secreted. In nonpathological circumstances, cellular location variability may indicate or may be because of species distinctions or strains [113].

\section{HSPs in Normal Eye}

The human fetal retina is contained in HSP70 in week 20-33 of growth, the same period of progress. In week 20-33 of development, the human fetal retina is present in HSP70, and the same duration of progress is established in nuclear layers. This may mean that the role of HSP70 is significant in normal retinal development [114], which is the same as an examination of the rat retina. In addition, another rat study found that retinal defense involves cells with HSP70 in bright light by Tezel and Wax was incubated with the HSP 27 antibody with a human retina. The cells were destroyed, and HSP 27 antibodies were suggested, and HSP 27 was avoided [115]. This caused death by the cells and suggested that the HSP 27anticorps prevented HSP 27 by binding. The discovery of HSP 27 in the normal retina is also endorsed. The retinal neuron failure by HSP 27antibodymediatedapoptoses in the ganglion cell layer was similarly observed by Tezel and Wax, which indicates that HSP 27 plays a significant part here. While there have not been many HSP tests on the human retinal tissue, several HSPs in the retina have been seen in many animal studies. Eyes of rat embryos were analyzed by Tanaka et al. HSC 70, HSP84, and HSP86 mRNAs were located in the rat embryo's retina. It was noticed that all three HSPs were located at high magnification on the neuroblastic layer of the retina. In the retinal pigment epithelium, HSP84 was also detected. In the mature rat retina, however, only HSC70 and HSP86 have been identified. Other animal experiments have also detected HSP70 close to that previously observed in HSP40 and HSP90.

\section{Role of HSP in DR}

Diabetes contributes to reductions in insulin-reliable organs (skeletal muscles, heart, liver, monocytes) in some heat shock proteins like HSP70 (HSP72) and heme oxygenase (HSP32). At the same time, the levels of HSPB2, HSPB3, and HSPB5 ( $\alpha$-B-crystalline) increased without improvements in the expression and decreased in the level of HSPB1 in the heart [116], with streptozotocin-induced (STZ-induced) diabetes. Similar improvements have been observed in the level of small heat shock proteins [117]. In retinal and crystalline lens 
diabetes caused by STZ, two crystallines ( $\alpha \mathrm{A}$ and $\alpha \mathrm{B}$ crystallines, HSPB4 and HSPB5, respectively) have been expressed. The expression of HespB1 remained unchanged and the expression of HSPB6 was decreased, and HSPB8 increased, respectively [118,119]. Related changes were observed in the retina of Ins2Akita in all crystalline forms [120].

Increased levels of $\alpha$-crystalline have been found to enhance cell survival for diabetes of the first type. During diabetes, however, expressed crystalline undergoes multiple posttranslator modifications, which reduces the association with pro-apoptotic Bax protein and thus cannot prevent retinal cell apoptosis even increased crystalline expression.

\section{HSP \& Apoptosis}

The form of death during embryogenesis is important, or programmed cell death is essential, and cell homeostasis is ensured latterly in the organism. Since treating with cytotoxins, apoptosis is a highly prevalent form of death of the cell.

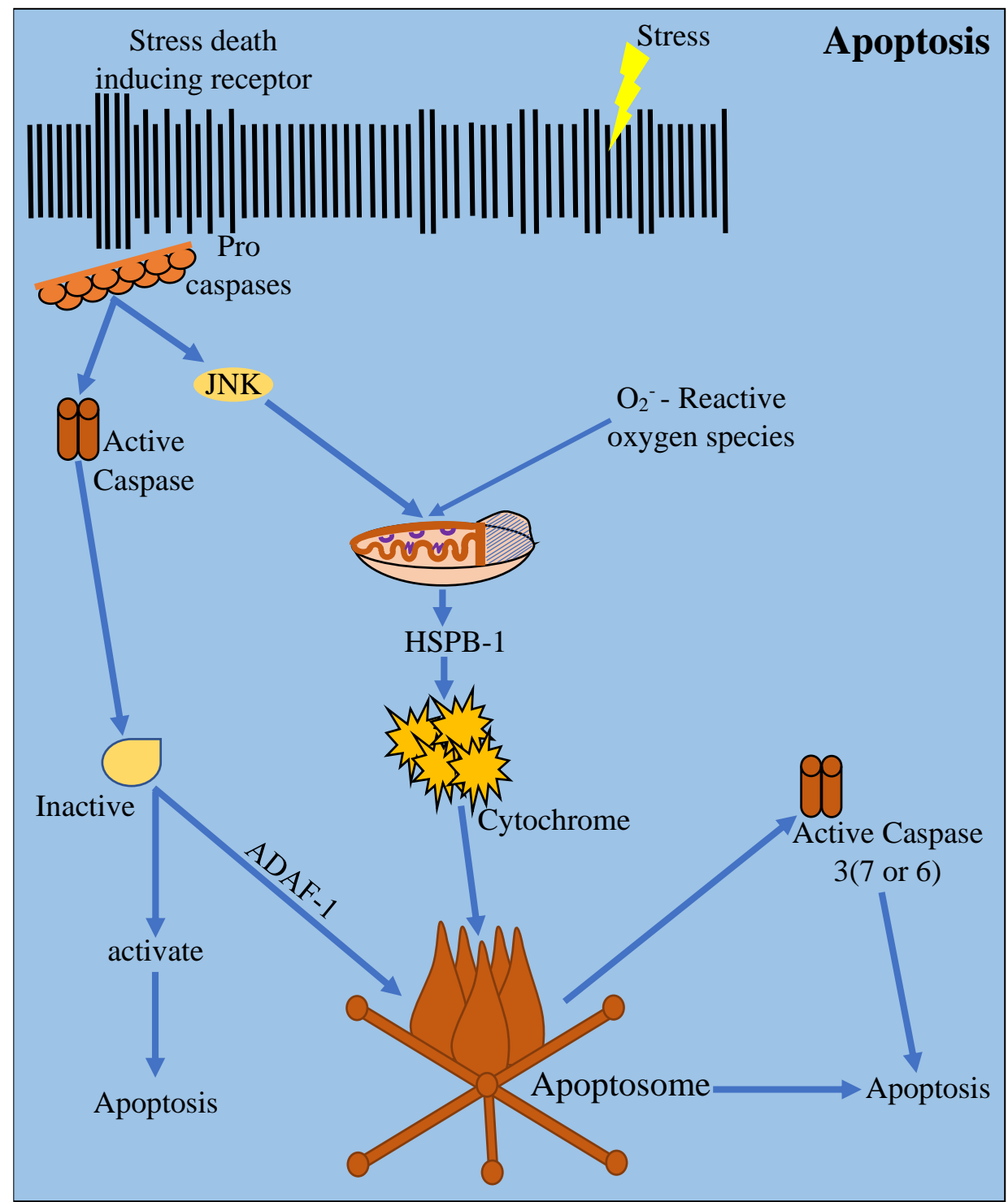

Figure 1. Representation of the intrinsic or mitochondrial trajectories and the direction of the extrinsic or deathreceptor tract.

Two mechanisms describe apoptotic processes regulated by a family of cysteine proteases called caspases-intrinsic or mitochondrial trajectories \& the direction of the extrinsic or death-receptor tract. The two signal transduction cascades converge at caspase-3, leading to 
the usual morphological and biochemical changes to the apoptotic cell. Cytochrome $\mathrm{C}$ interacts with the cytosome cytosome activation apoptotic protease (pro-caspase-9 and factor 1 (App1), Caspase-3 leads to complex activation (Figure 1) [121]. Other mitochondrial proteins, Smac and H-tra2, are responsible for apoptosis that neutralizes the apoptotic proteins' promoters. The mitochondrial molecule is associated with IAPs. The external pathway is regulated by the plasma membrane proteins of the TNF-receptor family called death receptors and contributes to the direct activation of receptor-proximal caspase- 8 or caspase- 10 death-mediated-signalingcompounds. Caspase- 8 may activate or cleave the down-stream cascade directly in an active form called t-Bid, which links extrinsic to intrinsic apoptotic routes through mitochondrial permeability.

HSPs revealed that the activation of caspases inhibits apoptosis. The excessive expression of HSSP 27, HSP 70 or HSP 60, and HSP 90 either inhibits apoptosis in several different cell models and prevents the caspase activation of various cellular tension, including the accumulation of malfunctions in protein reactive oxygen species (ROS) or DNA damage. HSPs may block the intrinsic and extrinsic apoptotic pathways at three levels by interfering with key proteins: (i) the mitochondria upstream, modulating signaling trajectories; (ii) Regulating the activation of apoptogen molecules at mitochondrial stage; (iii) postmitochondrial, by preventing later-phase apoptosis by any known drug or protein survival enhancement.

\subsection{Role of heat shock proteins 27 in apoptosis.}

Many heat shock proteins cause the inhibition of IKK beta and JNK. They are capable of suppressing NF-kappa B activation and are apparent in inhibiting IKK-beta activation. According to recent research, HSP 27 is already aware of a p38 mitogen-activated protein kinase (p38 MAP kinase) phosphorylation; HSP binds tightly to IKK beta to inhibit tumor necrosis (TNF treatment) activation [122]. HSP 27's over-expression is detected by HSP 27 gene-suppressing transfection, while TNF mediated activation of IKK-betas; by comparison, protein-further expression transfect small RNA-interfering potentials of TNFs, which are IKKbeta-activating. HSP 27 does not influence PKC-mediated potential effects on IKK-beta activation so far but, because PKC causes the activation of p38 MAP kinases, HSP 27 is expected to inhibit IKK-beta activation by PKC.

\subsection{Role of heat shock proteins 72 in apoptosis.}

An inhibitor of this pro-apoptotic kinase HSP72 [123] can shield cells from apoptosis regarding JNK while activating another. HSP72 binds to JNK and inhibits the JNK kinase SEK1 and mitogen active protein kinase 7 (MKK7) from being activated. Other researchers claim that HSP72 prevents the inactivation of JNK-focused phosphatase stress-mediated [124], thus retaining JNK in a dephosphorylated and inactive condition. HSP72's impact is not affected by its actions in ATPase but is not mediated by protein replenishment [125]. This demonstrates physiologically significance. The HSP72 has the potential to inhibit JNKactivation; the anti-sense of the HSP72 mRNA reduces the likelihood of a heat shock that inhibits JNK-mediated apoptosis caused by stress [126]. Since PKC activates JNK via SEK1 or MKK7 [127], HSP72 would further inhibit JNK activation triggered by PKC. The expression of Hs 72 in patients with insulin resistance has been shown to be poor in skeletal muscles, so it is the opposite of assessing insulin resistance [128, 129]. However, it is seen that this genetic 
determinant may be a genetic determinant of diabetes risk or that the legacy of a decreased capacity to synthesize HSP72 can increase the risk of insulin resistance since JNK function is up-regulated. In the same study, the expression of Hesp72 is also shown to be low in insulin resistance. These also suggest that induction of hydrogen shock protecting Insulin receptor substratum 1 (IRS-1) against inhibitors, serum phosphorylation and help to maintain insulin sensitivity could remove the activation of IKK beta and JN K induced by diacylglycerol and cytokines. This shows that the heat shock promotes the sensitivity of insulin.

\section{Diminished Wound Healing in Diabetes and the Possible Role of HSPs}

A diabetic foot ulcer is a big diabetes concern and poses a significant medical problem worldwide [130]. It affects about 170 million people worldwide. There are many considerations in the care of people who have diabetes. Hyperglycemia contributes to elevated immune cell glycosylation, such as neutrophils and macrophages, normal activity and chronic inflammatory predisposition, and increased toxicity sensitivity. Glycosylation of erythrocytes increases their rigidity, which in microvasculature can predispose local ischemia. These conditions predispose to microtrauma, foot defects, and ischemia [131], leading to their susceptibility to ulcers and deficiency of wound care in diabetes. Diabetic wound healing pathophysiological contains decreased or compromised development of the factor [132], angiogenesis [133] and leucocyte activity and chemotaxis [134], the migration and proliferation of keratinocytes and fibroblasts, epidermal neurological functions [135], collagen deposition, re-epithelialization, tissue granulation formation [136] and a re-modeling of the tissue through the matrix. Moreover, reducing the blood vessels within the wound edge contributes to tissue hypoxia and injury cure. There may also be some involvement in developing oxidative stress, irregular oxide, and disrupted redox status [137]. The importance and expression of HSPs as a defensive factor in the healing of wounds shows their importance for wounds' reaction. Diabetic states have a delayed expression of HSP72 at the protein level, irrespective of epithelial cells and inflammatory cells being upregulated by mRNA during the wound healing process. Alternatively, expression of HSP70 in the wound bed in the person with diabetes improved after a pause, indicating that the chronically open curative injury contributes to a higher HSP induction than a normally curative injury. Similarly, the levels of HSP70, HSP 60, and HSP 27 were increased in skin fibroblasts, patients with diabetic nephropathy [138]. Insulin administration and normalization of blood glucose levels could avoid the symptoms of diabetes [139].

\section{Medicinal Drugs for Raising HSP Levels}

Bimoclomol is an investigational medication that can increase membrane fluidity and increase the HSF-1 function, thereby increasing HSP70 levels. Bimoclomol has been noted to improve wound cure, minimize tissue injury, mitigate complications in diabetes, and increase insulin sensitivity in diabetes animal models [140]. Examples include hexamethyl glutaryl (HMG) metabolites CoA-reductase, carvediline, lipoic acid, and pentoxifyl metabolites. The low HSP72 standardization in 6 out of 9 patients with a low HSP72 level of leukocyte in patients suffering from type 1 diabetes and neuropathy has been linked with lipoic acid administration. The clinical neuropathy improvement was due to this finding in these patients. The rise in HSP has been reported as a workout, carvedilol, and thiazolidinediones. 
Thiazolidinediones are related to the increased mechanism in HSP70 levels in the pancreatic beta-cell, and the anti-inflammatory activity is related [141].

In clinical trials, outstanding effects on diabetes are consistent with medications that recover endothelium oxide, such as beta-adrenergic blockers, angiotensin enzyme conversion inhibitors; HMG-CoA reduces inhibitors and thiazolidinediones. Close-infrared therapy releases nitric oxide in the blood-vessel and thus increases diabetic neuropathy. Lastly, oral or intravenous administration of HSPs is somewhat inefficient as HSPs are predominantly intracellular molecules. However, the liposomal transmission of HSP72 into renal tubular cells has been reported as impeding the activation of the NF-kB factor of tumor necrosis and thus impeding ischemic-induced apoptosis. Bimoclomol is a unique medication that causes the expression of HSP. These drugs boost retinopathy for diabetes, neuropathy, nephropathy, accident remedies, cardiac ischemia, and insulin resistance in the in vivo model. Bimoclomol, through diabetes, increases the fluidity of negatively charged membrane lipids by upregulating HSP72 by HSF-1 disease. This effect is responsible for Bimoclomol one HSP's fatty acid structure and the membrane target cells' fluidity [142].

The lowering of the HSF-1 activation temperature cap into the physiological range causes indomethacin and other anti-inflammatory pharmaceutical products and sodium salicylate of DNA-binding activities for the HSF-1 gene itself. The synthesis and release of hyperphosphorylate in tissue and inflammatory conditions were shown. The HSF-1 stimulates and binds DNA, so it might be possible to make an HSP protein synthesis. In addition to indomethacin and arachidonic acid, phospholipase A2 decreases the thermal threshold for HSF-1 activation. Antiulcer geranylgeranylacetone was classified as a gastroprotection activation, HSP-1, and HSP 70 gene activation. Butyrate has been shown to improve HSP25 in rat calls and resistance to oxidative stress [143].

The heat shock response is strongly induced in a group of proteasome inhibitors by MG-132, lactacystin, and bortezomib. Some increase the number of malfunctions contributing to the HSF 1-dependent transcription, leading to unique HSP expression for proteasome drug pathways. Celastrol, potentially by transcriptional activation of proteasome inhibition, can also assist hyperphosphorylation and HSF-1. The new HSP induction to activate HSF-1 is tetracyclic acid. The origin is also linked to a rise in oxygen and reactive redox species. In conjunction with inhibitors such as radicicol and benzoquinone ansamycins, HSP90 and HSF1 have been recommended, which activate HSF-2 and induce HSP expression [144].

\section{HSP Proteins in Diabetic Retinopathy as a Therapeutic Option}

In an animal model, pharmacological induction of HSP72 expression increases the insulin response in type-2 diabetes. HSP72 mRNA is observed to be declining. Without HSP72, C-Jun N-terminal kinases (JNK), and IKK phosphorylates IRS-1 in Ser-307, the active insulin receptor is a weak substrate that inhibits the insulin signaller transduction via Akt (also called protein kinase B). HSP72 stops JNK and IKK from phosphorylating and triggers the activation of Akt, which plays two main roles in insulin-regulated glucose metabolism [145].

17.1. Translocation of glucose conveyors types 4 from the cytoplasm to the plasma membrane.

Glucose transfer into cells is a mechanism mediated by GLUTs. Insulin-dependent glucose absorption mainly mediated by the GLUT4 carriers, mainly expressed in mature 
muscle and fat tissues, is triggered by two different pathways in response to insulin: I to recruit transporters to the cell surface from intracellular ponds, \& (ii) to increase the carrier's function. Wortmannin inhibits these mechanisms individually. Inhibition of p38 mitogen-activated protein kinase (MAPK), on the contrary, says that MAPK p38 is involved exclusively in pathway-regulating activation of GLUT4 insulin stimulation. The divergence between the translocation of GLUT4 and operation and suggested GLUT4 regulatory structures is evident [146].

\subsection{Promotes glycogen synthesis by GSK-3 inactivation through serine phosphorylation.}

Glycogen synthase kinase 3 (GSK-3) is a protein kinase enzyme that controls glycogen synthesis in reaction to insulin. In various biological pathways, studies include GSK-3. GSK3 phosphorylates are easily phosphorylated in serine 21 in GSK-3 $\alpha$ or serine 9 in GSK-3 $\beta$ that stimuli with insulin or other growth factors further inhibit the GSK-3 kinase function. The implication is that threonine kinase B phosphorylates in phosphatidylinositol 3-Kinase (PI3K) are phosphorylated in vitro and in vivo PI3K-PKB signaling cascade decreases development factors. GSK-3 activity suppresses cell proliferation and cell viability since it is downstream from the PI3K-PKB pathway. This research recognizes GSK-3 phosphorylation, and the inactivity is independent of a PI3K-PKB functional process, and cAMP-dependent protein kinase-A (PKA) substrates are also used as serins-21 in GSK 3 alpha and 9 in GSK-3-beta. PKA is functionally active in all GSK-3 isoforms, phosphorylates, and inactivates. As a result, PKA acts parallel to PKB as a GSK-3 kinase and regulates a GSK-3 multifunctional enzyme [147].

\section{HSP70 for the Long-Term Treatment in Type 2 Mellitus Diabetes}

Physical workout can modulate HSP70, but workout can lead to cell tension, increasing long-term exercise iHSP70 in muscle, liver, kidneys, and heart skeletal development. Besides, another analysis found in the attenuation of HSP72 due to the exercises in skeletal-muscles, an animal model well-characterized as reflecting a person's condition with T2DM, is capable of showing a partial increase in insulin resistance in the body, a significant rise by a study in the appropriate animal concentration within exercise community compared to 50 percent on average higher in the heart.

\subsection{Translocation HSP70 modulation by hot tub therapy (HTT) as a clinical goal of T2DM.}

Strategies for modulation of HSP70 in T2DM sustain and increase HSP70 expression and avoid progression to more extreme T2DM. Several experiments indicate its ability to restore insulin sensitivity. HSP70 has the potential to become the therapeutic target in Type-2DM treatment, considering many of its functions. The hot tub therapy (HTT) method regulates HSP70. The HTT procedure does not entail rigorous physical training, so it helps patients with T2DM who cannot exercise. A study conducted reveals that HTT diabetes, HSP 70, can be treated, the lipid profile, antioxidant, insulin secretion increased, and AGE is greatly decreased instead of the untreated diabetes model. However, HTT affects muscle mass and blood glucose levels significantly. The lipid profile also improved as triglyceride (TG) levels, total cholesterol (TC) and low-density cholesterol lipoproteins (LDL-c) increases significantly. However, HTT showed deterioration in all three lipid profiles. For HTT, on the other side, the reduction in HDL-c in diabetic form was substantially increased [148]. 
18.2. Modulation of HSP70 as a therapeutic target in T2DM by HSP70 internasal administration.

Direct HSP70 administration raises the body HSP70 level. HSP70 administration is a plant derivative known as Medicago sativa; the alpha HSP70 composition is identical to the body naturally developed HSP70, so it has little variation. An alpha HSP 70 analysis in the DM animal model indicates a decline in hemoglobin A1C (HbA1C). Since there was no size and less time for analysis, the result was not important.

Alpha HSP70 administration also impacts the enhancement of insulin response. Intraperitoneal testing of the hypothesis was performed before the HSP70 was provided in diabetic models. The insulin sensitivity indicated a $14 \%$ and $40 \%$ increase after $10 \mu \mathrm{g}$ and $40 \mu \mathrm{g}$, respectively, after administering an HSP 70. This reveals reduced blood glucose levels after treatment of aHSP70 and reduced insulin levels after aHSP70. Reduced blood glucose levels are supported by lowered insulin sensitivities and increased insulin use by the body $[147,148]$.

\section{HSP70 Suppression of New Therapeutics: ROS, Antioxidants, and Hexosamine Pathway}

Physical Glutamine, an amido-transferase of fructose-6-phosphate, is the pace determination step of the hexosamine biological pathway that is used in the overproduction of fructose 6-phosphate as an alternative mechanism to glycolysis by the excessive $\mathrm{N}$-acetyl glucosamine and inhibition of TGF and $\beta$ gene expression of fructoses. This overexpression contributes to multiple detrimental metabolic, endothelial and retinal neuron apoptosis diseases. Suitable compounds have been identified to alleviate metabolic and functional defects in diabetic retinopathy. Instead of inhibiting the hexosamine pathway only, cardio-vascular symptoms triggered by hyperglycemia, such as antioxidant suppression, are suppressed in WAS-406 (2-acetamide-1,3,6-tri-O-acetyl-2,4-dideoxy-alpha-D-Xylo-hexopyranose). Rhein, a rhubarb-isolated anthraquinone drug, reduces the hexosamine receptor and effective in treating experimented diabetic nephropathy. Benfotiamine converts fructose- 6 phosphate into pentose-5 phosphates, which reduces the flow by the hexosamine pathway. Benfotiamine, lipid-soluble thiamine, can also clinically help inhibit diabetic bacteria from evolving and progressing due to vascular damage from hyperglycemia in tandem with AGE progression and PKC pathways. A study demonstrates that benfotiamine can also prevent hyperglycemia-is associated with NF-kappaB activation, leading to activating the transketolase pentosephosphate pathway-enzyme, further conversion of glyceraldehyde-3-phosphate and fructose-6 phosphate into pentose-5, and other sugars [148].

Other tests have also been studied in animal models, including vitamins $\mathrm{C}$ and $\mathrm{E}$, in addition to lipoic acids. Many of them have seen advances in biochemistry, and diabetes and diabetic problems are not established. The possible advantage of vitamin $\mathrm{E}$ has been demonstrated in DR by non-enzymatic pathways by its free radical scavenger behavior in the cell's extracellular part. Trolox is a vitamin E water-soluble and strong antioxidant. By reducing membrane lipid peroxidation, Trolox has shown prevention in the depletion of pericytes in diabetic rats partly.

\section{Immunohistochemical Analysis Under HSP-60 and HSP-27}

Chronic retina ischemia induces lowered vascular perfusion and is considered, particularly in normal intraocular tension, to be a cause of glaucoma pathogenesis. Apoptosis 
in glaucomatous optic neuropathy is a retinal cell mortality mechanism. Immunohistochemical research showed that HSP 60 and HSP 27 are relatively higher in glaucoma than in human nonglaucomatous skin. In glaucoma optic neuropathy, HSP 60 and HSP 27 may also be part of a protective mechanism. High levels of HSP 27 and HSP72 in retinal ganglion cells are shown after an ischemic phase is induced by elevated intraocular pressure. The elevated intraocular pressure in the animal model was found primarily in glia cells due to HSP 27 and the phosphorylated HSP 27 [148]. It indicates that HSP72 is associated with improved survival of retinal ganglion cells in the animal model of acute glaucoma. In vivo and in vitro retinal models, however, glaucoma is associated with strong serum sHSP antibodies that promote retinal cell apoptosis. The HSPs can stimulate the T cells, which facilitate apoptosis in the retinal ganglion. HSPs can also be exposed to increased expression in glaucoma eyes as immune targets inducing neural apoptosis, diminishing HSPs' protection.

\section{Laser Therapy}

Laser therapy choices continue to grow for retinal disease, and ST laser may be used for retinal disease treatment. More optimization of laser settings would be required for ST laser to work as a mono-therapy. The dosing of laser therapies is more complex than medical decisions of structured dosing regimens; the common techniques are laser strength and machine automatic density. A boring option for the future is to upright those genetic pathways with complex algorithms for laser therapy. We need more studies on how laser power contributes to gene regulation improvements, leading to potential laser therapy that may upregulate those gene pathways selectively. The transmission of viral vectors to particular cell populations may also be imagined in the future and induced explicitly by specific laser wavelengths or electricity settings. On request, the ophthalmologist would temporarily check therapy gene expression in cells triggered by laser. Laser phototherapy was the first retinal disease therapies and laser therapies, such as ST laser, emerge as additional therapeutic options for retinal disease via continued analysis on laser interaction with the retinal tissue [58].

\section{Way Forward}

Whenever hot, cold, ischemia or glucose, or other lack of oxygen, HSPs are under tension in any cell or body. Heat shock proteins provide thermo-tolerance of a cell or organism. This reaction provides heat protection and can guard against a whole other lethal stress by means of a process called cross-tolerance.

Recently, metformin, a widely used diabetes drug, has been identified as a modulator for inflammation linked to ER tension. These results specifically shed new light on this agent and add another positive statement for the global debate on metformin status (gestational diabetes mellitus) GDM therapy. In particular, a promising path for future study is the prophylactic use of the compound to avoid GDM. Different chemicals have been shown to minimize ER tension and enhance insulin signaling, including tauroursodeoxycholic acid (TUDCA) and 4 phenylbutyrate (4-PBA). TUDCA GDM therapy may be a promising policy for reducing inflammation and enhancing the tolerance to peripheral insulin. While this approach sounds appealing, it would be a far-reaching therapy.

In the mechanism of adapting endogenous stress to many tissues, chaperones play a significant role. However, the modified chaperone function has been related to the development of many diseases; hence a recent and evolving pharmaceutical development area has been 
chaperone modulators [149]. Recently, HSP90 inhibitors have been a promising method for battling multiple cancers. On the other hand, chaperone induction activation has proven successful in healing from various disorders, such as ischemia, cardiac diseases, diabetes, and neurodegeneration [150]. Different HSP modulators have already been developed in clinical phases. Due to the positive findings, particular chaperone modulators may be potential industry blockbusters for multiple therapeutic indications.

Diabetic retinopathy reduction is simple if the levels of blood sugar and blood pressure are kept under control. These two causes play a significant role in delaying the disease's progression. Meeting the eye specialist at least once a year for a full eye test is strongly recommended if you have diabetes.

\section{Conclusions}

HSP experiments have significant drawbacks in diabetes complications. Changes in HSP expression in the DM-complicated target organ can be hard to understand because increased expression can indicate the direct involvement of HSPs in the pathogens, countervailing cytoprotective reactions, and the two at separate stages of the disease. A potentially contradictory interpretation can be provided of the contrasting effect of intra/extracell HSPs on HSP diabetic complications [150]. Thus, intracellular or extracellular intervention studies are essential for a deep understanding of HSP's DM complications function. It is also increasingly understood that HSPs act in a network and, thus, abnormal HSP clusters are very relevant. HSPs can also be produced out of the cells in Extracellular vesicles (EV), representing an important new cell to cell approach. There is a particular concern with the potential use of HSPs as therapeutic targets. Because DM triggers disrupted protein aggregation, oxidative pressure, altered mitochondrial bioenergetics, and apoptosis, the boosting of the HSP cytoprotective machinery tends to be a strategy that is ideal for preventing and/or minimize the production of DM complications. Furthermore, the recent identification in cancer research of compounds that can simply and safely increase/decrease HSP levels paved the way for pharmacologic intervention tests, which often target HSPs in other pathological situations, including DM-related complications. The method of tissue targeting may also be important, as pharmacological control of DM complications in different vascular beds may have adverse effects. In diabetes, factors such as inflammation, glycemia, and beta-cell survival can cause serious HSP complications. To understand the role and complications of HSPs and their antibodies in diabetes at the very least, future research on functional foods influencing the level of anti-HSP antibodies is necessary. In HSP extracellular changes, a comparatively low transient stress response is unfortunately noticeable. It may serve as a signaling reaction instead of a higher intracellular HSP. HSPs are a protein group suffocated by their molecular mass (in kilodaltons; $\mathrm{kDa}$ ). In a broad range of conditions, including protein reaction, in many physiological modifications, Chaperones provide adequate cell activity and function.

\section{Funding}

None.

\section{Acknowledgments}

The authors express gratitude to Chitkara College of Pharmacy, Chitkara University, Punjab, India, for motivational support for this review's compilation. 


\section{Conflict of Interest}

The authors declare no conflict of interest.

\section{References}

1. Lyon, M.S.; Milligan, C. Extracellular heat shock proteins in neurodegenerative diseases: New perspectives. Neurosci. Lett. 2019, 711, 134462, https://doi.org/10.1016/j.neulet.2019.134462.

2. Fatima, F.; Nadeem, A.; Javed, M. Molecular characterization of heat shock protein 70-1 gene of Capra aegagrus blythi. Pak. J. Zool. 2019, 51, https://doi.org/10.17582/journal.pjz/2019.51.1.195.203.

3. Sottile, M.L.; Nadin, S.B. Heat shock proteins and DNA repair mechanisms: an updated overview. Cell Stress Chaperones 2018, 23, 303-315, https://doi.org/10.1007/s12192-017-0843-4.

4. Ganesan, S.; Summers, C.M.; Pearce, S.C.; Gabler, N.K.; Valentine, R.J.; Baumgard, L.H.; Rhoads, R.P.; Selsby, J.T. Short-term heat stress altered metabolism and insulin signaling in skeletal muscle. J. Anim. Sci. 2018, 96, 154-167, https://doi.org/10.1093/jas/skx083.

5. Corigliano, M.G.; Sander, V.A.; Sánchez López, E.F.; Ramos Duarte, V.A.; Mendoza Morales, L.F.; Angel, S.O.; Clemente, M. Heat Shock Proteins 90 kDa: Immunomodulators and Adjuvants in Vaccine Design Against Infectious Diseases. Frontiers in Bioengineering and Biotechnology 2021, 8, 1532, https://doi.org/10.3389/fbioe.2020.622186.

6. Cangeri Di Naso, F.; Rosa Porto, R.; Sarubbi Fillmann, H.; Maggioni, L.; Vontobel Padoin, A.; Jacques Ramos, R.; Corá Mottin, C.; Bittencourt, A.; Anair Possa Marroni, N.; Ivo Homem de Bittencourt Jr, P. Obesity depresses the anti-inflammatory HSP70 pathway, contributing to NAFLD progression. Obesity 2015, 23, 120-129, https://doi.org/10.1002/oby.20919.

7. Labbadia, J.; Cunliffe, H.; Weiss, A.; Katsyuba, E.; Sathasivam, K.; Seredenina, T.; Woodman, B.; Moussaoui, S.; Frentzel, S.; Luthi-Carter, R.; Paganetti, P.; Bates, G.P. Altered chromatin architecture underlies progressive impairment of the heat shock response in mouse models of Huntington disease. The Journal of Clinical Investigation 2011, 121, 3306-3319, https://doi.org/10.1172/jci57413.

8. Gupte, A.A.; Bomhoff, G.L.; Morris, J.K.; Gorres, B.K.; Geiger, P.C. Lipoic acid increases heat shock protein expression and inhibits stress kinase activation to improve insulin signaling in skeletal muscle from high-fatfed rats. J. Appl. Physiol. 2009, 106, 1425-1434, https://doi.org/10.1152/japplphysiol. 91210.2008.

9. Gupte, A.A.; Bomhoff, G.L.; Swerdlow, R.H.; Geiger, P.C. Heat Treatment Improves Glucose Tolerance and Prevents Skeletal Muscle Insulin Resistance in Rats Fed a High-Fat Diet. Diabetes 2009, 58, 567, https://doi.org/10.2337/db08-1070.

10. Henstridge, D.C.; Bruce, C.R.; Drew, B.G.; Tory, K.; Kolonics, A.; Estevez, E.; Chung, J.; Watson, N.; Gardner, T.; Lee-Young, R.S.; Connor, T.; Watt, M.J.; Carpenter, K.; Hargreaves, M.; McGee, S.L.; Hevener, A.L.; Febbraio, M.A. Activating HSP72 in Rodent Skeletal Muscle Increases Mitochondrial Number and Oxidative Capacity and Decreases Insulin Resistance. Diabetes 2014, 63, 1881, https://doi.org/10.2337/db130967.

11. Kavanagh, K.; Davis, A.T.; Jenkins, K.A.; Flynn, D.M. Effects of heated hydrotherapy on muscle HSP70 and glucose metabolism in old and young vervet monkeys. Cell Stress Chaperones 2016, 21, 717-725, https://doi.org/10.1007/s12192-016-0699-z.

12. Rogers, R.S.; Morris, E.M.; Wheatley, J.L.; Archer, A.E.; McCoin, C.S.; White, K.S.; Wilson, D.R.; Meers, G.M.E.; Koch, L.G.; Britton, S.L.; Thyfault, J.P.; Geiger, P.C. Deficiency in the Heat Stress Response Could Underlie Susceptibility to Metabolic Disease. Diabetes 2016, 65, 3341, https://doi.org/10.2337/db16-0292.

13. Silverstein, M.G.; Ordanes, D.; Wylie, A.T.; Files, D.C.; Milligan, C.; Presley, T.D.; Kavanagh, K. Inducing Muscle Heat Shock Protein 70 Improves Insulin Sensitivity and Muscular Performance in Aged Mice. The Journals of Gerontology: Series A 2015, 70, 800-808, https://doi.org/10.1093/gerona/glu119.

14. Cruz, A.M.; Beall, C. Extracellular ATP Increases Glucose Metabolism in Skeletal Muscle Cells in a P2 Receptor Dependent Manner but Does Not Contribute to Palmitate-Induced Insulin Resistance. Front. Physiol. 2020, 11, 1188, https://doi.org/10.3389/fphys.2020.567378.

15. Kurucz, I.; Morva, Á.; Vaag, A.; Eriksson, K.-F.; Huang, X.; Groop, L.; Koranyi, L. Decreased Expression of Heat Shock Protein 72 In Skeletal Muscle of Patients With Type 2 Diabetes Correlates With Insulin Resistance. Diabetes 2002, 51, 1102, https://doi.org/10.2337/diabetes.51.4.1102.

16. Henstridge, D.C.; Forbes, J.M.; Penfold, S.A.; Formosa, M.F.; Dougherty, S.; Gasser, A.; de Courten, M.P.; Cooper, M.E.; Kingwell, B.A.; de Courten, B. The relationship between heat shock protein 72 expression in 
skeletal muscle and insulin sensitivity is dependent on adiposity. Metabolism 2010, 59, 1556-1561, https://doi.org/10.1016/j.metabol.2010.01.027.

17. Chung, J.; Nguyen, A.-K.; Henstridge, D.C.; Holmes, A.G.; Chan, M.H.S.; Mesa, J.L.; Lancaster, G.I.; Southgate, R.J.; Bruce, C.R.; Duffy, S.J.; Horvath, I.; Mestril, R.; Watt, M.J.; Hooper, P.L.; Kingwell, B.A.; Vigh, L.; Hevener, A.; Febbraio, M.A. HSP72 protects against obesity-induced insulin resistance. Proceedings of the National Academy of Sciences 2008, 105, 1739, https://doi.org/10.1073/pnas.0705799105.

18. Matos, M.A.d.; Ottone, V.d.O.; Duarte, T.C.; Sampaio, P.F.d.M.; Costa, K.B.; Fonseca, C.A.; Neves, M.P.C.; Schneider, S.M.; Moseley, P.; Coimbra, C.C.; Magalhães, F.d.C.; Rocha-Vieira, E.; Amorim, F.T. Exercise reduces cellular stress related to skeletal muscle insulin resistance. Cell Stress Chaperones 2014, 19, 263270, https://doi.org/10.1007/s12192-013-0453-8.

19. Zhu, G.; Yin, F.; Wang, L.; Wei, W.; Jiang, L.; Qin, J. Modeling type 2 diabetes-like hyperglycemia in C. elegans on a microdevice. Integrative Biology 2016, 8, 30-38, https://doi.org/10.1039/c5ib00243e.

20. Kavanagh, K.; Wylie, A.T.; Chavanne, T.J.; Jorgensen, M.J.; Voruganti, V.S.; Comuzzie, A.G.; Kaplan, J.R.; McCall, C.E.; Kritchevsky, S.B. Aging Does Not Reduce Heat Shock Protein 70 in the Absence of Chronic Insulin Resistance. The Journals of Gerontology: Series A 2012, 67, 1014-1021, https://doi.org/10.1093/gerona/gls008.

21. Quin, G.J.; Len, A.C.L.; Billson, F.A.; Gillies, M.C. Proteome map of normal rat retina and comparison with the proteome of diabetic rat retina: New insight in the pathogenesis of diabetic retinopathy. Proteomics 2007, 7, 2636-2650, https://doi.org/10.1002/pmic.200600486.

22. Déry, M.-A.C.; Michaud, M.D.; Richard, D.E. Hypoxia-inducible factor 1: regulation by hypoxic and nonhypoxic activators. The International Journal of Biochemistry \& Cell Biology 2005, 37, 535-540, https://doi.org/10.1016/j.biocel.2004.08.012.

23. Ramya Krishna, V.; Aswani Dutt, V.; Ashim, K.M. Hypoxia-Inducible Factor-1 (HIF-1): A Potential Target for Intervention in Ocular Neovascular Diseases. Curr. Drug Targets 2013, 14, 919-935, https://doi.org/10.2174/13894501113149990015.

24. Sultan, M.B.; Zhou, D.; Loftus, J.; Dombi, T.; Ice, K.S.; Macugen Study, G. A phase 2/3, multicenter, randomized, double-masked, 2-year trial of pegaptanib sodium for the treatment of diabetic macular edema. Ophthalmology 2011, 118, 1107-1118, https://doi.org/10.1016/j.ophtha.2011.02.045.

25. Gomez-Pastor, R.; Burchfiel, E.T.; Thiele, D.J. Regulation of heat shock transcription factors and their roles in physiology and disease. Nature Reviews Molecular Cell Biology 2018, 19, 4-19, https://doi.org/ 10.1038/nrm.2017.73.

26. Pierce, A.; Wei, R.; Halade, D.; Yoo, S.-E.; Ran, Q.; Richardson, A. A Novel mouse model of enhanced proteostasis: Full-length human heat shock factor 1 transgenic mice. Biochem. Biophys. Res. Commun. 2010, 402, 59-65, https://doi.org/10.1016/j.bbrc.2010.09.111.

27. Li, J.; Labbadia, J.; Morimoto, R.I. Rethinking HSF1 in stress, development, and organismal health. Trends Cell Biol. 2017, 27, 895-905, https://doi.org/10.1016/j.tcb.2017.08.002.

28. Kern, A.; Ackermann, B.; Clement, A.M.; Duerk, H.; Behl, C. HSF1-Controlled and Age-Associated Chaperone Capacity in Neurons and Muscle Cells of C. elegans. PLoS One 2010, 5, e8568, https://doi.org/10.1371/journal.pone.0008568.

29. Sayed, K.M.; Mahmoud, A.A. Heat shock protein-70 and hypoxia inducible factor-1 $\alpha$ in type 2 diabetes mellitus patients complicated with retinopathy. Acta Ophthalmol. (Copenh.) 2016, 94, e361-e366, https://doi.org/10.1111/aos.12919.

30. Lincoln, V.; Tang, X.; Chen, M.; Li, W. Extracellular HSP90 $\alpha$ versus intracellular HSP90 $\beta$ in wound healing and cancer. In Heat Shock Proteins. Springer International Publishing, 2019; pp. 289-315. https://doi.org/10.1007/978-3-030-03952-3_15.

31. Moreira-de-Sousa, C.; de Souza, R.B.; Fontanetti, C.S. HSP70 as a biomarker: an excellent tool in environmental contamination analysis-a review. Water Air Soil Pollut. 2018, 229(8). https://doi.org/10.1007/s11270-018-3920-0.

32. Chidlow, G.; Wood, J.P.M.; Casson, R.J. Expression of Inducible Heat Shock Proteins Hsp27 and Hsp70 in the Visual Pathway of Rats Subjected to Various Models of Retinal Ganglion Cell Injury. PLoS One 2014, 9 , e114838, https://doi.org/10.1371/journal.pone.0114838.

33. Tezel, G.; Hernandez, M.R.; Wax, M.B. Immunostaining of Heat Shock Proteins in the Retina and Optic Nerve Head of Normal and Glaucomatous Eyes. Arch. Ophthalmol. 2000, 118, 511-518, https://doi.org/10.1001/archopht.118.4.511. 
34. Chien, C.-C.; Huang, C.-J.; Tien, L.-T.; Cheng, Y.-C.; Ke, C.-Y.; Lee, Y.-J. Suppression of HSP27 Restores Retinal Function and Protects Photoreceptors From Apoptosis in a Light-Induced Retinal Degeneration Animal Model. Invest. Ophthalmol. Vis. Sci. 2017, 58, 3107-3117, https://doi.org/10.1167/iovs.16-21007.

35. Bhat, S.; Kumar, P.; Kashyap, N.; Deshmukh, B.; Dige, M.S.; Bhushan, B.; Chauhan, A.; Kumar, A.; Singh, G. Effect of heat shock protein 70 polymorphism on thermotolerance in Tharparkar cattle. Veterinary world 2016, 9, 113, https://doi.org/10.14202/vetworld.2016.113-117.

36. Joachim, S.C.; Bruns, K.; Lackner, K.J.; Pfeiffer, N.; Grus, F.H. Antibodies to $\alpha$ B-Crystallin, Vimentin, and Heat Shock Protein 70 in Aqueous Humor of Patients with Normal Tension Glaucoma and IgG Antibody Patterns Against Retinal Antigen in Aqueous Humor. Curr. Eye Res. 2007, 32, 501-509, https://doi.org/10.1080/02713680701375183.

37. Kregel, K.C. Heat shock proteins: modifying factors in physiological stress responses and acquired thermotolerance. J. Appl. Physiol. 2002, 92, 2177-2186, https://doi.org/10.1152/japplphysiol.01267.2001.

38. Hennessy, F.; Nicoll, W.S.; Zimmermann, R.; Cheetham, M.E.; Blatch, G.L. Not all J domains are created equal: Implications for the specificity of Hsp40-Hsp70 interactions. Protein Sci. 2005, 14, 1697-1709, https://doi.org/10.1110/ps.051406805.

39. Krueger-Naug, A.M.R.; Emsley, J.G.; Myers, T.L.; Currie, R.W.; Clarke, D.B. Injury to retinal ganglion cells induces expression of the small heat shock protein Hsp27 in the rat visual system. Neuroscience 2002, 110, 653-665, https://doi.org/10.1016/s0306-4522(01)00453-5.

40. Diamant, S.; Eliahu, N.; Rosenthal, D.; Goloubinoff, P. Chemical chaperones regulate molecular chaperones in vitro and in cells under combined salt and heat stresses. J. Biol. Chem. 2001, 276, 39586-39591, https://doi.org/10.1074/jbc.m103081200.

41. Gao, B.; Tsan, M.-F. Endotoxin contamination in recombinant human heat shock protein 70 (Hsp70) preparation is responsible for the induction of tumor necrosis factor $\alpha$ release by murine macrophages. J. Biol. Chem. 2003, 278, 174-179, https://doi.org/10.1074/jbc.m208742200.

42. Miller, D.J.; Fort, P.E. Heat Shock Proteins Regulatory Role in Neurodevelopment. Front. Neurosci. 2018, 12, 821, https://doi.org/10.3389/fnins.2018.00821.

43. Kremmer, S.; Kreuzfelder, E.; Klein, R.; Bontke, N.; Henneberg-Quester, K.B.; Steuhl, K.P.; Grosse-Wilde, H. Antiphosphatidylserine antibodies are elevated in normal tension glaucoma. Clin. Exp. Immunol. 2001, 125, 211-215, https://doi.org/10.1046/j.1365-2249.2001.01578.x.

44. Ikeda, Y.; Maruyama, I.; Nakazawa, M.; Ohguro, H. Clinical Significance of Serum Antibody Against Neuron-Specific Enolase in Glaucoma Patients. Jpn. J. Ophthalmol. 2002, 46, 13-17, https://doi.org/10.1016/s0021-5155(01)00455-5.

45. Wax, M.B.; Tezel, G.; Kawase, K.; Kitazawa, Y. Serum autoantibodies to heat shock proteins in glaucoma patients from Japan and the United States. Ophthalmology 2001, 108, 296-302, https://doi.org/10.1016/s0161-6420(00)00525-x.

46. Molecular Chaperones and Cell Signalling; Henderson, B., Pockley, A.G., Eds.; Cambridge University Press: Cambridge, 2005; https://doi.org/10.1017/cbo9780511546310.

47. Lorenz, K.; Beck, S.; Keilani, M.M.; Wasielica-Poslednik, J.; Pfeiffer, N.; Grus, F.H. Course of serum autoantibodies in patients after acute angle-closure glaucoma attack. Clin. Experiment. Ophthalmol. 2017, 45, 280-287, https://doi.org/10.1111/ceo.12864.

48. Foster, N.L.; Lukowiak, K.; Henry, T.B. Time-related expression profiles for heat shock protein gene transcripts (HSP40, HSP70) in the central nervous system of Lymnaea stagnalis exposed to thermal stress. Commun. Integr. Biol. 2015, 8, e1040954, https://doi.org/10.1080/19420889.2015.1040954.

49. Kampinga, H.H.; Hageman, J.; Vos, M.J.; Kubota, H.; Tanguay, R.M.; Bruford, E.A.; Cheetham, M.E.; Chen, B.; Hightower, L.E. Guidelines for the nomenclature of the human heat shock proteins. Cell Stress Chaperones 2009, 14, 105-111, https://doi.org/10.1007/s12192-008-0068-7.

50. Bechtold, D.A.; Brown, I.R. Induction of Hsp27 and Hsp32 Stress Proteins and Vimentin in Glial Cells of the Rat Hippocampus Following Hyperthermia. Neurochem. Res. 2003, 28, 1163-1173, https://doi.org/10.1023/a:1024268126310.

51. Athanasiou, D.; Aguilà, M.; Bevilacqua, D.; Novoselov, S.S.; Parfitt, D.A.; Cheetham, M.E. The cell stress machinery and retinal degeneration. FEBS Lett. 2013, 587, 2008-2017, https://doi.org/10.1016/j.febslet.2013.05.020.

52. Taguchi, T.; Nazneen, A.; Al-Shihri, A.A.; A. Turkistani, K.; Razzaque, M.S. Heat Shock Protein 47: A Novel Biomarker of Phenotypically Altered Collagen-Producing Cells. Acta Histochem. Cytochem. 2011, 44, 35-41, https://doi.org/10.1267/ahc.11001. 
53. Rocnik, E.; Chow Lawrence, H.; Pickering, J.G. Heat Shock Protein 47 Is Expressed in Fibrous Regions of Human Atheroma and Is Regulated by Growth Factors and Oxidized Low-Density Lipoprotein. Circulation 2000, 101, 1229-1233, https://doi.org/10.1161/01.cir.101.11.1229.

54. Kitamura, H.; Yamamoto, S.; Nakase, H.; Matsuura, M.; Honzawa, Y.; Matsumura, K.; Takeda, Y.; Uza, N.; Nagata, K.; Chiba, T. Role of heat shock protein 47 in intestinal fibrosis of experimental colitis. Biochem. Biophys. Res. Commun. 2011, 404, 599-604, https://doi.org/10.1016/j.bbrc.2010.12.006.

55. Dai, C. The heat-shock, or HSF1-mediated proteotoxic stress, response in cancer: from proteomic stability to oncogenesis. Philosophical Transactions of the Royal Society B: Biological Sciences 2018, 373, 20160525, https://doi.org/10.1098/rstb.2016.0525.

56. Franklin, T.B.; Krueger-Naug, A.M.; Clarke, D.B.; Arrigo, A.P.; Currie, R.W. The role of heat shock proteins Hsp70 and Hsp27 in cellular protection of the central nervous system. Int. J. Hyperthermia 2005, 21, 379392, https://doi.org/10.1080/02656730500069955.

57. Latchman, D.S. HSP27 and cell survival in neurones. Int. J. Hyperthermia 2005, 21, 393-402, https://doi.org/10.1080/02656730400023664.

58. Moore, S.M.; Chao, D.L. Application of subthreshold laser therapy in retinal diseases: a review. Expert Review of Ophthalmology 2018, 13, 311-320, https://doi.org/10.1080/17469899.2018.1555035.

59. Krueger-Naug, A.M.R.; Hopkins, D.A.; Armstrong, J.N.; Plumier, J.-C.L.; Currie, R.W. Hyperthermic induction of the 27-kDa heat shock protein (Hsp27) in neuroglia and neurons of the rat central nervous system. J. Comp. Neurol. 2000, 428, 495-510, https://doi.org/10.1002/1096-9861(20001218) 428:3<495::aidcne7>3.0.co;2-4

60. Fleshner, M.; Campisi, J.; Amiri, L.; Diamond, D.M. Cat exposure induces both intra- and extracellular Hsp72: the role of adrenal hormones. Psychoneuroendocrinology 2004, 29, 1142-1152, https://doi.org/10.1016/j.psyneuen.2004.01.007.

61. Heise, E.A.; Fort, P.E. Impact of diabetes on alpha-crystallins and other heat shock proteins in the eye. $J$. Ocul. Biol. Dis. Infor. 2011, 4, 62-69, https://doi.org/10.1007/s12177-011-9073-7.

62. Turturici, G.; Geraci, F.; Candela, M.E.; Giudice, G.; Gonzalez, F.; Sconzo, G. Hsp70 localizes differently from chaperone Hsc70 in mouse mesoangioblasts under physiological growth conditions. J. Mol. Histol. 2008, 39, 571, https://doi.org/10.1007/s10735-008-9197-7.

63. West, J.D.; Wang, Y.; Morano, K.A. Small Molecule Activators of the Heat Shock Response: Chemical Properties, Molecular Targets, and Therapeutic Promise. Chem. Res. Toxicol. 2012, 25, 2036-2053, https://doi.org/10.1021/tx300264x.

64. Horowitz, M.; Robinson, S.D. Heat shock proteins and the heat shock response during hyperthermia and its modulation by altered physiological conditions. Prog. Brain Res. 2007, 162, 433-446, https://doi.org/10.1016/S0079-6123(06)62021-9.

65. Calderwood, S.K. Heat shock proteins and cancer: intracellular chaperones or extracellular signalling ligands? Philosophical Transactions of the Royal Society B: Biological Sciences 2018, 373, 20160524, https://doi.org/10.1098/rstb.2016.0524.

66. Zuehlke, A.D.; Moses, M.A.; Neckers, L. Heat shock protein 90: its inhibition and function. Philosophical Transactions of the Royal Society B: Biological Sciences 2018, 373, 20160527, https://doi.org/10.1098/rstb.2016.0527.

67. Willis, M.S.; Patterson, C. Hold Me Tight: Role of the Heat Shock Protein Family of Chaperones in Cardiac Disease. Circulation 2010, 122, 1740-1751, https://doi.org/10.1161/circulationaha.110.942250.

68. Pockley, A.G. Heat shock proteins in health and disease: therapeutic targets or therapeutic agents? Expert Rev. Mol. Med. 2001, 3, 1-21, https://doi.org/10.1017/s1462399401003556.

69. Zilaee, M.; Shirali, S. Heat shock proteins and diabetes. Canadian journal of diabetes 2016, 40, 594-602, https://doi.org/10.1016/j.jcjd.2016.05.016.

70. Lee, J.-H.; Gao, J.; Kosinski, P.A.; Elliman, S.J.; Hughes, T.E.; Gromada, J.; Kemp, D.M. Heat shock protein 90 (HSP90) inhibitors activate the heat shock factor 1 (HSF1) stress response pathway and improve glucose regulation in diabetic mice. Biochem. Biophys. Res. Commun. 2013, 430, 1109-1113, https://doi.org/10.1016/j.bbrc.2012.12.029.

71. Buchner, J.; Li, J. Structure, function and regulation of the hsp90 machinery. Biomedical journal 2013, 36, 106, https://doi.org/10.4103/2319-4170.113230.

72. Das, S.; Bhattacharyya, N.P. Huntingtin interacting protein HYPK is a negative regulator of heat shock response and is downregulated in models of Huntington's Disease. Exp. Cell Res. 2016, 343(2), 107-117, https://doi.org/10.1016/j.yexcr.2016.03.021. 
73. Kitson, R.R.A.; Moody, C.J. Learning from Nature: Advances in Geldanamycin- and Radicicol-Based Inhibitors of Hsp90. J. Org. Chem. 2013, 78, 5117-5141, https://doi.org/10.1021/jo4002849.

74. Hermane, J.; Eichner, S.; Mancuso, L.; Schröder, B.; Sasse, F.; Zeilinger, C.; Kirschning, A. New geldanamycin derivatives with anti Hsp properties by mutasynthesis. Org. Biomol. Chem. 2019, 17, 52695278, https://doi.org/10.1039/c9ob00892f.

75. Trepel, J.; Mollapour, M.; Giaccone, G.; Neckers, L. Targeting the dynamic HSP90 complex in cancer. Nature Reviews Cancer 2010, 10, 537-549, https://doi.org/10.1038/nrc2887.

76. Böttger, E.; Multhoff, G. Role of Heat Shock Proteins in Immune Modulation in Malaria. In Heat Shock Proteins of Malaria, Shonhai, A., Blatch, G.L., Eds. Springer Netherlands: Dordrecht, 2014; https://doi.org/10.1007/978-94-007-7438-4_7.

77. Caplan, A.J. What is a co-chaperone? Cell Stress Chaperones 2003, 8, 105-107, https://doi.org/10.1379/14661268(2003)008<0105:wiac >2.0.co;2.

78. Tsan, M.-F.; Gao, B. Heat shock proteins and immune system. J. Leukocyte Biol. 2009, 85, 905-910, https://doi.org/10.1189/jlb.0109005.

79. Grotegut, P.; Hoerdemann, P.J.; Reinehr, S.; Gupta, N.; Dick, H.B.; Joachim, S.C. Heat shock protein 27 injection leads to caspase activation in the visual pathway and retinal t-cell response. Int. J. Mol. Sci. 2021, 22(2), 513, https://doi.org/10.3390/ijms22020513.

80. Voegeli, T.S.; Wintink, A.J.; Chen, Y.; Currie, R.W. Heat shock proteins 27 and 70 regulating angiotensin II-induced NF-кB: a possible connection to blood pressure control? Appl. Physiol. Nutr. Metab. 2008, 33, 1042-1049, https://doi.org/10.1139/h08-068.

81. Yenari, M.A. Heat Shock Proteins and Neuroprotection. In Molecular and Cellular Biology of Neuroprotection in the CNS, Alzheimer, C., Ed. Springer US: Boston, MA, 2002; https://doi.org/10.1007/978-1-4615-0123-7_10.

82. Tezel, G.; Yang, X.; Luo, C.; Kain, A.D.; Powell, D.W.; Kuehn, M.H.; Kaplan, H.J. Oxidative Stress and the Regulation of Complement Activation in Human Glaucoma. Invest. Ophthalmol. Vis. Sci. 2010, 51, 50715082, https://doi.org/10.1167/iovs.10-5289.

83. Murakami, S.; Toda, Y.; Seki, T.; Munetomo, E.; Kondo, Y.; Sakurai, T.; Furukawa, Y.; Matsuyama, M.; Nagate, T.; Hosokawa, N. Heat shock protein (HSP) 47 and collagen are upregulated during neointimal formation in the balloon-injured rat carotid artery. Atherosclerosis 2001, 157, 361-368, https://doi.org/10.1016/s0021-9150(00)00743-7.

84. Rowles, J.E.; Keane, K.N.; Gomes Heck, T.; Cruzat, V.; Verdile, G.; Newsholme, P. Are Heat Shock Proteins an Important Link between Type 2 Diabetes and Alzheimer Disease? Int. J. Mol. Sci. 2020, 21, https://doi.org/10.3390/ijms21218204.

85. Bellini, S.; Barutta, F.; Mastrocola, R.; Imperatore, L.; Bruno, G.; Gruden, G. Heat Shock Proteins in Vascular Diabetic Complications: Review and Future Perspective. Int. J. Mol. Sci. 2017, 18, https://doi.org/10.3390/ijms18122709.

86. Nishino, T.; Miyazaki, M.; Abe, K.; Furusu, A.; Mishima, Y.; Harada, T.; Ozono, Y.; Koji, T.; Kohno, S. Antisense oligonucleotides against collagen-binding stress protein HSP47 suppress peritoneal fibrosis in rats. Kidney Int. 2003, 64, 887-896, https://doi.org/10.1046/j.1523-1755.2003.00169.x.

87. Razzaque, M.S.; Foster, C.S.; Ahmed, A.R. Role of Collagen-Binding Heat Shock Protein 47 and Transforming Growth Factor- $\beta 1$ in Conjunctival Scarring in Ocular Cicatricial Pemphigoid. Invest. Ophthalmol. Vis. Sci. 2003, 44, 1616-1621, https://doi.org/10.1167/iovs.02-0644.

88. Febbraio, M.A.; Mesa, J.L.; Chung, J.; Steensberg, A.; Keller, C.; Nielsen, H.B.; Krustrup, P.; Ott, P.; Secher, N.H.; Pedersen, B.K. Glucose ingestion attenuates the exercise-induced increase in circulating heat shock protein 72 and heat shock protein 60 in humans. Cell Stress Chaperones 2004, 9, 390-396, https://doi.org/10.1379/csc-24r1.1.

89. Hekmatimoghaddam, S.; Zare-Khormizi, M.R.; Pourrajab, F. Underlying mechanisms and chemical/biochemical therapeutic approaches to ameliorate protein misfolding neurodegenerative diseases. Biofactors 2017, 43(6), 737-759, https://doi.org/10.1002/biof.1264.

90. Marineli, R.d.S.; Moura, C.S.; Moraes, É.A.; Lenquiste, S.A.; Lollo, P.C.B.; Morato, P.N.; Amaya-Farfan, J.; Maróstica, M.R. Chia (Salvia hispanica L.) enhances HSP, PGC-1 $\alpha$ expressions and improves glucose tolerance in diet-induced obese rats. Nutrition 2015, 31, 740-748, https://doi.org/10.1016/j.nut.2014.11.009.

91. Neueder, A.; Achilli, F.; Moussaoui, S.; Bates, G.P. Novel isoforms of heat shock transcription factor 1, HSF $1 \gamma \alpha$ and HSF $1 \gamma \beta$, regulate chaperone protein gene transcription. J. Biol. Chem. 2014, 289, 19894-19906, https://doi.org/10.1074/jbc.m114.570739. 
92. Dong, Y.; Miller, L.P.; Sanders, J.G.; Somero, G.N. Heat-Shock Protein 70 (Hsp70) Expression in Four Limpets of the Genus Lottia: Interspecific Variation in Constitutive and Inducible Synthesis Correlates With in situ Exposure to Heat Stress. The Biological Bulletin 2008, 215, 173-181, https://doi.org/10.2307/25470698.

93. Böttinger, L.; Oeljeklaus, S.; Guiard, B.; Rospert, S.; Warscheid, B.; Becker, T. Mitochondrial heat shock protein (Hsp) 70 and Hsp10 cooperate in the formation of Hsp60 complexes. J. Biol. Chem. 2015, 290, 1161111622, https://doi.org/10.1074/jbc.m115.642017.

94. Shevtsov, M.; Huile, G.; Multhoff, G. Membrane heat shock protein 70: a theranostic target for cancer therapy. Philosophical Transactions of the Royal Society B: Biological Sciences 2018, 373, 20160526, https://doi.org/10.1098/rstb.2016.0526.

95. Triantafilou, K.; Triantafilou, M.; Dedrick, R.L. A CD14-independent LPS receptor cluster. Nat. Immunol. 2001, 2, 338-345, https://doi.org/10.1038/86342.

96. Pockley, A.G.; Henderson, B.; Multhoff, G. Extracellular cell stress proteins as biomarkers of human disease. Biochem. Soc. Trans. 2014, 42, 1744-1751, https://doi.org/10.1042/bst20140205.

97. Jeffery, C.J. Protein moonlighting: what is it, and why is it important? Philosophical Transactions of the Royal Society B: Biological Sciences 2018, 373, 20160523, https://doi.org/10.1098/rstb.2016.0523.

98. Datta, K.; Rahalkar, K.; Dinesh, D.K. Heat Shock Proteins (Hsp): Classifications and its involvement in health and disease. J Pharma Care Health Sys 2017, 4, 1-3, https://doi.org/10.4172/2376-0419.1000175.

99. Bolhassani, A.; Rafati, S. Heat-shock proteins as powerful weapons in vaccine development. Expert Review of Vaccines 2008, 7, 1185-1199, https://doi.org/10.1586/14760584.7.8.1185.

100.Ganesan, S.; Summers, C.M.; Pearce, S.C.; Gabler, N.K.; Valentine, R.J; Baumgard, L.H.; Rhoads, R.P.; Selsby, J.T. Short-term heat stress causes altered intracellular signaling in oxidative skeletal muscle. J. Anim. Sci. 2017, 95(6), 2438-2451, https://doi.org/10.2527/jas.2016.1233.

101.Joachim, S.C.; Wax, M.B.; Boehm, N.; Dirk, D.R.; Pfeiffer, N.; Grus, F.H. Upregulation of Antibody Response to Heat Shock Proteins and Tissue Antigens in an Ocular Ischemia Model. Invest. Ophthalmol. Vis. Sci. 2011, 52, 3468-3474, https://doi.org/10.1167/iovs.10-5763.

102. Frank, R.N. Diabetic Retinopathy. N. Engl. J. Med. 2004, 350(1), 48-58, https://doi.org/10.1056/nejmra021678.

103.Hahn, J.-S. The Hsp90 chaperone machinery: from structure to drug development. BMB reports 2009, 42 , 623-630, https://doi.org/10.5483/bmbrep.2009.42.10.623.

104.Sevin, M.; Girodon, F.; Garrido, C.; de Thonel, A. HSP90 and HSP70: Implication in Inflammation Processes and Therapeutic Approaches for Myeloproliferative Neoplasms. Mediators Inflamm. 2015, 2015, 970242, https://doi.org/10.1155/2015/970242.

105.O'Neill, S.; Harrison, E.M.; Ross, J.A.; Wigmore, S.J.; Hughes, J. Heat-Shock Proteins and Acute Ischaemic Kidney Injury. Nephron Experimental Nephrology 2014, 126, 167-174, https://doi.org/10.1159/000363323.

106.Kim, J.Y.; Sohn, H.J.; Seo, J.H. Characterization of the antigenic phenotype of $\alpha$ B-crystallin-expressing peripapillary glial cells in the developing chick retina. Anat. Cell Biol. 2011, 44, 35, https://doi.org/10.5115/acb.2011.44.1.35.

107.Waters, E.R.; Rioflorido, I. Evolutionary Analysis of the Small Heat Shock Proteins in Five Complete Algal Genomes. J. Mol. Evol. 2007, 65, 162-174, https://doi.org/10.1007/s00239-006-0223-7.

108.De, S.; Rabin, D.M.; Salero, E.; Lederman, P.L.; Temple, S.; Stern, J.H. Human Retinal Pigment Epithelium Cell Changes and Expression of $\alpha \mathrm{B}-$ Crystallin: A Biomarker for Retinal Pigment Epithelium Cell Change in Age-Related Macular Degeneration. Arch. Ophthalmol. 2007, 125, 641-645, https://doi.org/10.1001/archopht.125.5.641.

109. Gene Expression in Cornea and Lens. In Eye, Retina, and Visual System of the Mouse, The MIT Press: 2008; https://doi.org/10.7551/mitpress/7578.003.0065.

110.Sreekumar, P.G.; Kannan, R.; Kitamura, M.; Spee, C.; Barron, E.; Ryan, S.J.; Hinton, D.R. $\alpha$ B Crystallin Is Apically Secreted within Exosomes by Polarized Human Retinal Pigment Epithelium and Provides Neuroprotection to Adjacent Cells. PLoS One 2010, 5, e12578, https://doi.org/10.1371/journal.pone.0012578.

111.Jin, J.K.; Whittaker, R.; Glassy, M.S.; Barlow, S.B.; Gottlieb, R.A.; Glembotski, C.C. Localization of phosphorylated $\alpha \mathrm{B}$-crystallin to heart mitochondria during ischemia-reperfusion. American Journal of Physiology-Heart and Circulatory Physiology 2008, 294, H337-H344, https://doi.org/10.1152/ajpheart.00881.2007. 
112.Kannan, R.; Sreekumar, P.G.; Hinton, D.R. Novel roles for $\alpha$-crystallins in retinal function and disease. Progress in retinal and eye research. 2012, 31(6), 576-604, https://doi.org/10.1016/j.preteyeres.2012.06.001.

113. Kowluru, R.A.; Kowluru, A.; Mishra, M.; Kumar, B. Oxidative stress and epigenetic modifications in the pathogenesis of diabetic retinopathy. Prog. Retin. Eye Res. 2015, 48, 40-61, https://doi.org/10.1016/j.preteyeres.2015.05.001.

114. Rodríguez-Iturbe, B.; Johnson, R.J. Heat shock proteins and cardiovascular disease. Physiol. Int. 2018, 105(1), 19-37, https://doi.org/10.1556/2060.105.2018.1.4.

115.Takeda, K.; Kusachi, S.; Ohnishi, H.; Nakahama, M.; Murakami, M.; Komatsubara, I.; Oka, T.; Doi, M.; Ninomiya, Y.; Tsuji, T. Greater than normal expression of the collagen-binding stress protein heat-shock protein-47 in the infarct zone in rats after experimentally-induced myocardial infarction. Coron. Artery Dis. 2000, 11(1), 57-68, https://doi.org/10.1097/00019501-200002000-00011.

116. Sewelam, N.; Kazan, K.; Hüdig, M.; Maurino, V.G.; Schenk, P.M. The AtHSP17.4C1 Gene Expression Is Mediated by Diverse Signals that Link Biotic and Abiotic Stress Factors with ROS and Can Be a Useful Molecular Marker for Oxidative Stress. Int. J. Mol. Sci. 2019, 20, https://doi.org/10.3390/ijms20133201.

117.Pasupuleti, N.; Matsuyama, S.; Voss, O.; Doseff, A.I.; Song, K.; Danielpour, D.; Nagaraj, R.H. The antiapoptotic function of human $\alpha \mathrm{A}$-crystallin is directly related to its chaperone activity. Cell Death Dis. 2010, 1, e31-e31, https://doi.org/10.1038/cddis.2010.3.

118.Park, K.-J.; Gaynor, R.B.; Kwak, Y.T. Heat shock protein 27 association with the IкB kinase complex regulates tumor necrosis factor $\alpha$-induced NF-kB activation. J. Biol. Chem. 2003, 278, 35272-35278, https://doi.org/10.1074/jbc.m305095200.

119.Hooper, P.L.; Hooper, P.L. Inflammation, heat shock proteins, and type 2 diabetes. Cell Stress Chaperones 2009, 14, 113-115, https://doi.org/10.1007/s12192-008-0073-X.

120.Kitano, S.; Kondo, T.; Matsuyama, R.; Ono, K.; Goto, R.; Takaki, Y.; Hanatani, S.; Sakaguchi, M.; Igata, M.; Kawashima, J.; Motoshima, H.; Matsumura, T.; Kai, H.; Araki, E. Impact of hepatic HSP72 on insulin signaling. American Journal of Physiology-Endocrinology and Metabolism 2018, 316, E305-E318, https://doi.org/10.1152/ajpendo.00215.2018.

121.Park, H.-S.; Lee, J.-S.; Huh, S.-H.; Seo, J.-S.; Choi, E.-J. Hsp72 functions as a natural inhibitory protein of c-Jun N-terminal kinase. The EMBO Journal 2001, 20, 446-456, https://doi.org/10.1093/emboj/20.3.446.

122.Gabai, V.L.; Meriin, A.B.; Yaglom, J.A.; Wei, J.Y.; Mosser, D.D.; Sherman, M.Y. Suppression of stress kinase JNK is involved in HSP72-mediated protection of myogenic cells from transient energy deprivation: HSP72 alleviates the stress-induced inhibition of JNK dephosphorylation. J. Biol. Chem. 2000, 275, 3808838094, https://doi.org/10.1074/jbc.m006632200.

123.Tournier, C.; Hess, P.; Yang, D.D.; Xu, J.; Turner, T.K.; Nimnual, A.; Bar-Sagi, D.; Jones, S.N.; Flavell, R.A.; Davis, R.J. Requirement of JNK for Stress- Induced Activation of the Cytochrome c-Mediated Death Pathway. Science 2000, 288, 870, https://doi.org/10.1126/science.288.5467.870.

124.Wild, S.; Roglic, G.; Green, A.; Sicree, R.; King, H. Global Prevalence of Diabetes. Diabetes Care 2004, 27, 1047, https://doi.org/10.2337/diacare.27.5.1047.

125.Safi, S.Z.; Qvist, R.; Kumar, S.; Batumalaie, K.; Ismail, I.S.B. Molecular Mechanisms of Diabetic Retinopathy, General Preventive Strategies, and Novel Therapeutic Targets. BioMed Research International 2014, 2014, 801269, https://doi.org/10.1155/2014/801269.

126. Galkowska, H.; Wojewodzka, U.; Olszewski, W.L. Chemokines, cytokines, and growth factors in keratinocytes and dermal endothelial cells in the margin of chronic diabetic foot ulcers. Wound Repair Regen. 2006, 14, 558-565, https://doi.org/10.1111/j.1743-6109.2006.00155.x.

127. Falanga, V. Wound healing and its impairment in the diabetic foot. The Lancet 2005, 366, 1736-1743, https://doi.org/10.1016/s0140-6736(05)67700-8.

128. Galiano, R.D.; Tepper, O.M.; Pelo, C.R.; Bhatt, K.A.; Callaghan, M.; Bastidas, N.; Bunting, S.; Steinmetz, H.G.; Gurtner, G.C. Topical vascular endothelial growth factor accelerates diabetic wound healing through increased angiogenesis and by mobilizing and recruiting bone marrow-derived cells. The American journal of pathology 2004, 164, 1935-1947, https://doi.org/10.1016/s0002-9440(10)63754-6.

129.Spenny, M.L.; Muangman, P.; Sullivan, S.R.; Bunnett, N.W.; Ansel, J.C.; Olerud, J.E.; Gibran, N.S. Neutral endopeptidase inhibition in diabetic wound repair. Wound Repair Regen. 2002, 10, 295-301, https://doi.org/10.1046/j.1524-475x.2002.10504.x.

130.Lobmann, R.; Ambrosch, A.; Schultz, G.; Waldmann, K.; Schiweck, S.; Lehnert, H. Expression of matrixmetalloproteinases and their inhibitors in the wounds of diabetic and non-diabetic patients. Diabetologia 2002, 45, 1011-1016, https://doi.org/10.1007/s00125-002-0868-8. 
131.Puricelli, L.; Iori, E.; Millioni, R.; Arrigoni, G.; James, P.; Vedovato, M.; Tessari, P. Proteome Analysis of Cultured Fibroblasts from Type 1 Diabetic Patients and Normal Subjects. The Journal of Clinical Endocrinology \& Metabolism 2006, 91, 3507-3514, https://doi.org/10.1210/jc.2006-0274.

132. Maruyama, K.; Asai, J.; Ii, M.; Thorne, T.; Losordo, D.W.; D'Amore, P.A. Decreased macrophage number and activation lead to reduced lymphatic vessel formation and contribute to impaired diabetic wound healing. The American journal of pathology 2007, 170, 1178-1191, https://doi.org/10.2353/ajpath.2007.060018.

133. Galkowska, H.; Wojewodzka, U.; Olszewski, W.L. Low recruitment of immune cells with increased expression of endothelial adhesion molecules in margins of the chronic diabetic foot ulcers. Wound Repair Regen. 2005, 13(3), 248-254, https://doi.org/10.1111/j.1067-1927.2005.130306.x.

134.Fang, X.; Yu, S.X.; Lu, Y.; Bast, R.C.; Woodgett, J.R.; Mills, G.B. Phosphorylation and inactivation of glycogen synthase kinase 3 by protein kinase A. Proceedings of the National Academy of Sciences 2000, 97, 11960, https://doi.org/10.1073/pnas.220413597.

135. Markussen, L.K.; Winther, S.; Wicksteed, B.; Hansen, J.B. GSK3 is a negative regulator of the thermogenic program in brown adipocytes. Sci. Rep. 2018, 8, 3469, https://doi.org/10.1038/s41598-018-21795-y.

136.Lobmann, R.; Zemlin, C.; Motzkau, M.; Reschke, K.; Lehnert, H. Expression of matrix metalloproteinases and growth factors in diabetic foot wounds treated with a protease absorbent dressing. J. Diabetes Complications 2006, 20(5), 329-335, https://doi.org/10.1016/j.jdiacomp.2005.08.007.

137.Tchénio, T.; Havard, M.; Martinez, L.A.; Dautry, F. Heat Shock-Independent Induction of Multidrug Resistance by Heat Shock Factor 1. Mol. Cell. Biol. 2006, 26, 580, https://doi.org/10.1128/mcb.26.2.580591.2006.

138.Pei, H.; Lou, Z.; Wang, L. Emerging role of FKBP51 in AKT kinase/protein kinase B signaling. Cell Cycle 2010, 9, 6-7, https://doi.org/10.4161/cc.9.1.10290.

139.Polakowski, J.S.; Wegner, C.D.; Cox, B.F. Bimoclomol elevates heat shock protein 70 and cytoprotects rat neonatal cardiomyocytes. Eur. J. Pharmacol. 2002, 435, 73-77, https://doi.org/10.1016/s00142999(01)01551-5.

140.Li, H.-B.; Dai, C.-G.; Hu, Y. Characterization and expression analysis of genes encoding three small heat shock proteins in the oriental armyworm, Mythimna separata (Walker). PLoS One 2020, 15, e0235912, https://doi.org/10.1371/journal.pone.0235912

141. Miova, B.; Dimitrovska, M.; Dinevska-Kjovkarovska, S.; V Esplugues, J.; Apostolova, N. The heat stress response and diabetes: More room for mitochondrial implication. Curr. Pharm. Des. 2016, 22(18), 26192639, https://doi.org/10.2174/1381612822666160203114738.

142.Kubota, H.; Yamamoto, S.; Itoh, E.; Abe, Y.; Nakamura, A.; Izumi, Y.; Okada, H.; Iida, M.; Nanjo, H.; Itoh, H.; Yamamoto, Y. Increased expression of co-chaperone HOP with HSP90 and HSC70 and complex formation in human colonic carcinoma. Cell Stress Chaperones 2010, 15(6), 1003-1111, https://doi.org/10.1007/s12192-010-0211-0.

143.Mulyani, W.R.W.; Sanjiwani, M.I.D.; Sandra, I.; Lestari, A.A.W.; Wihandani, D.M.; Suastika, K.; Saraswati, M.R.; Bhargah, A.; Manuaba, I.B.A.P. Chaperone-based therapeutic target innovation: Heat shock protein 70 (HSP70) for Type 2 diabetes mellitus. Diabetes, metabolic syndrome and obesity: targets and therapy 2020, 13, 559, https://doi.org/10.2147/dmso.s232133.

144. Nayak Rao, S. The role of heat shock proteins in kidney disease. Journal of Translational Internal Medicine 2016, 4, 114-117, https://doi.org/10.1515/jtim-2016-0034.

145.Henderson, B. Integrating the cell stress response: a new view of molecular chaperones as immunological and physiological homeostatic regulators. Cell Biochem. Funct. 2010, 28, 1-14, https://doi.org/10.1002/cbf.1609.

146.Mahgoub, S.; Youns, M.; Bassyouni, A.; Hassan, Z. Serum levels of heat shock protein 27 as a potential marker of diabetic nephropathy in Egyptians with type 2 diabetes. Journal of Applied Pharmaceutical Science 2012, 2, 014-020, https://doi.org/10.7324/japs.2012.21104.

147.Atalay, M.; Oksala, N.; Lappalainen, J.; Laaksonen, D.E; Sen, C.K.; Roy, S. Heat shock proteins in diabetes and wound healing. Curr. Protein Pept. Sci. 2009, 10(1), 85-95, https://doi.org/10.2174/138920309787315202.

148. Andley, U.P. Crystallins in the eye: Function and pathology. Prog. Retin. Eye Res. 2007, 26, 78-98, https://doi.org/10.1016/j.preteyeres.2006.10.003.

149. Chimini, G.; Rubartelli, A. Novel pathways of protein secretion. Molecular Chaperones and Cell Signaling 2005, 45-60, https://doi.org/10.1017/cbo9780511546310.004. 
150.Urban, M.J.; Dobrowsky, R.T.; Blagg, B.S.J. Heat shock response and insulin-associated neurodegeneration. Trends Pharmacol. Sci. 2012, 33, 129-137, https://doi.org/10.1016/j.tips.2011.11.001. 